San Jose State University

SJSU ScholarWorks

Master's Theses

Master's Theses and Graduate Research

1998

\title{
Effects of coach interactions on college soccer players' behavior and perception
}

Jeffrey Scott Cardinal

San Jose State University

Follow this and additional works at: https://scholarworks.sjsu.edu/etd_theses

\section{Recommended Citation}

Cardinal, Jeffrey Scott, "Effects of coach interactions on college soccer players' behavior and perception" (1998). Master's Theses. 1725.

DOI: https://doi.org/10.31979/etd.zemb-rzg9

https://scholarworks.sjsu.edu/etd_theses/1725

This Thesis is brought to you for free and open access by the Master's Theses and Graduate Research at SJSU ScholarWorks. It has been accepted for inclusion in Master's Theses by an authorized administrator of SJSU ScholarWorks. For more information, please contact scholarworks@sjsu.edu. 


\section{INFORMATION TO USERS}

This manuscript has been reproduced from the microfilm master. UMI films the text directly from the original or copy submitted. Thus, some thesis and dissertation copies are in typewriter face, while others may be from any type of computer printer.

The quality of this reproduction is dependent upon the quality of the copy submitted. Broken or indistinct print, colored or poor quality illustrations and photographs, print bleedthrough, substandard margins, and improper alignment can adversely affect reproduction.

In the unlikely event that the author did not send UMI a complete manuscript and there are missing pages, these will be noted. Also, if unauthorized copyright material had to be removed, a note will indicate the deletion.

Oversize materials (e.g., maps, drawings, charts) are reproduced by sectioning the original, beginning at the upper left-hand corner and continuing from left to right in equal sections with small overlaps. Each original is also photographed in one exposure and is included in reduced form at the back of the book.

Photographs included in the original manuscript have been reproduced xerographically in this copy. Higher quality 6" 19 " black and white photographic prints are available for any photographs or illustrations appearing in this copy for an additional charge. Contact UMI directly to order.

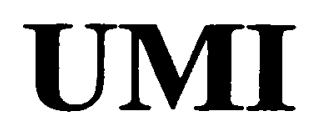

A Bell \& Howell Information Company 



\title{
EFFECTS OF COACH INTERACTIONS ON COLLEGE SOCCER PLAYERS'
} BEHAVIOR AND PERCEPTION

\author{
A Thesis \\ Presented to \\ The Faculty of the Department of Human Performance \\ San Jose State University \\ In Partial Fulfillment \\ Of the Requirements for the Degree \\ Master of Arts \\ by \\ Jeffrey Scott Cardinal
}

August, 1998 
UMI Number: 1392722

Copyright 1998 by Cardinal, Jeffrey scott

All rights reserved.

UMI Microform 1392722

Copyright 1999, by UMI Company. All rights reserved.

This microform edition is protected against unauthorized copying under Title 17, United States Code.

\section{UMI \\ 300 North Zeeb Road \\ Ann Arbor, MI 48103}


๑) 1998

Jeffrey Scott Cardinal

\section{ALL RIGHTS RESERVED}


APPROVED FOR THE DEPARTMENT OF HL MAN PERFORMANCE Soon Willinsm

Dr. Susan Wilkinson

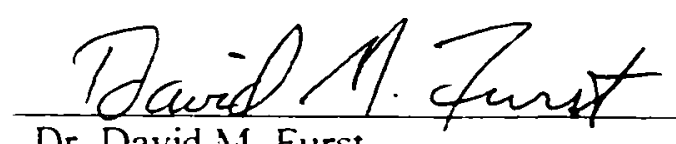

Dr. David M. Furst

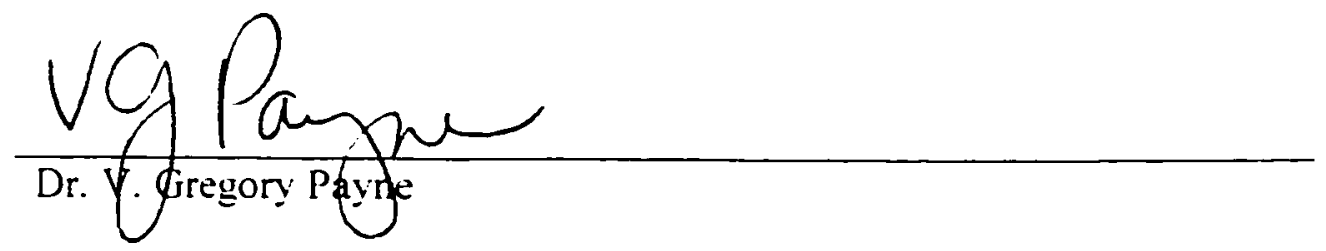

APPROVED FOR THE UNIVERSITY

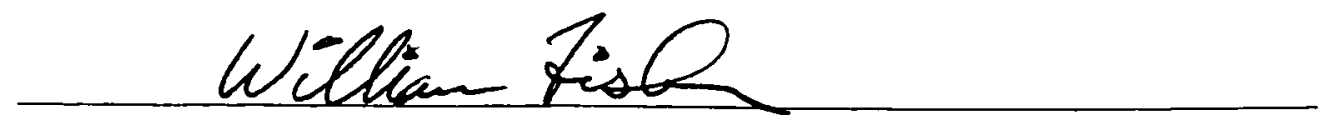




\section{ABSTRACT \\ EFFECTS OF COACH INTERACTIONS ON COLLEGE SOCCER PLAYERS' BEHAVIOR AND PERCEPTION \\ by Jeffrey Scott Cardinal}

The purposes of the study were to determine the effects of a coach's verbal interactions on athlete effort as measured by motor skill engagement, to determine which goal orientation(s) the coach encouraged and if the coach provided equitable motivation to all types of athletes and to determine coach's and athletes' perceptions of the coach's verbal interactions. Data were reported for 1 coach and 25 athletes who finished the season. Despite the coach's focus on positive interactions and its relationship to motor skill engagement, nonstarter task athletes were able to achieve high levels of motor skill engagement with less positive coach interactions. The coach was found to encourage a task oriented environment. There were mixed results as to the accuracy of the coach's perception of his actual behaviors and the athletes' perception of the coach's behaviors. In particular, the nonstarter athletes generally had a different perception of the coach's behaviors. 


\section{Acknowledgements}

I would like to thank all San Jose State University professors who have helped me through this process.

Specifically, I would like to thank Dr. Barbara J. Conry for all her enthusiasm, humanistic skills, and for making an effort to be on my thesis committee.

I would like to thank my thesis committee members for agreeing to help with this project and for all their feedback. Dr. David M. Furst, for his sport psychology expertise and for helping me to stay focused on my thesis topic, and Dr. V. Gregory Payne, for teaching me the research process and exemplifying how to be a true professional.

I would like to thank Dr. Susan Wilkinson, my thesis committee chair, for sharing with me her knowledge on teaching, her expertise on sport pedagogy, and for her patience and effort in helping me to complete this thesis.

I would like to thank the following individuals for giving me feedback on my masters thesis via e-mail. I do not personally know these individuals, however their dedication to this profession was evident in the help they gave me: Gordon Bloom, Fresno State University; Jean Cote, Brock University; Joan Duda, Purdue University; Alan Lacy, Indiana State University; Thom McKenzie and Brent Rushall, San Diego State University; Ron Smith and Frank Smoll; University of Washington; and Hans van der Mars, Oregon State University.

In addition, I would like to thank Mr. Lawrence F. Aguiar, Las Positas College, an extraordinary role model and source of guidance from the Introduction to Physical 
Education class all the way through the completion of my master's degree and for allowing me to conduct my thesis on his Las Positas College soccer team.

I would like to thank my parents, Jeffrey P. Cardinal and Lorna M. Cardinal, and my brother Trevor R. Cardinal for all the love and support they have given me through all these years.

Finally, I would like to thank my wife Nancy A. Cardinal, for all her support, patience, and independence in completing my masters degree. 


\section{Table of Contents}

Chapter 1 Introduction.............................................

Statement of the Problem..................................... 8

Statement of Purpose.........................................

Research Questions........................................10

Assumptions............................................... 10

Delimitations............................................... 10

Limitations....................................................1

Definitions................................................. 1

Chapter 2 Review of Literature

Introduction ................................................

Systematic Observation in the Classroom and in Physical

Education.....................................................

Systematic Observation of Coaching Behaviors..................15

Systematic Observation of Coaching Behaviors of Successful and Non-Successful Coaches...............................16

Systematic Observation of Coach and Athlete Behaviors..........26

Coaching Effectiveness: Psychological Affects of Coaching

Behaviors.....................................................

Achievement Motivation....................................... 40

Studies Examining Achievement Motivation in Sport..............44

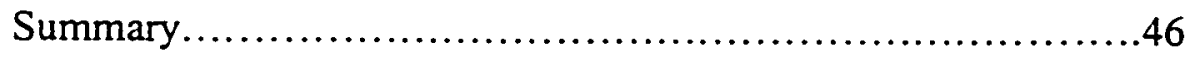


Chapter 3 Methods

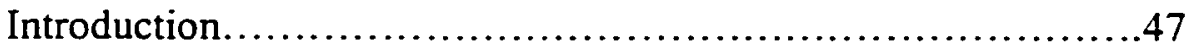

Subjects....................................................... 48

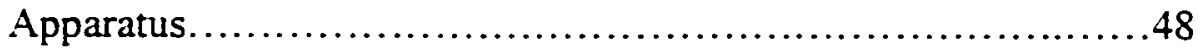

Instruments..................................................

Observation of the Coach: CBAS...............................50

Observation of the Athlete: MSE............................5 1

Athlete and Coach Perceptions of Coaching Behaviors...........51

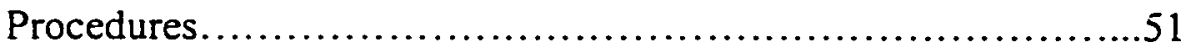

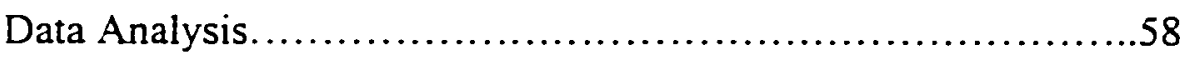

Chapter 4 Results and Discussion

Athlete Goal Orientation and Status..........................59

Time Spent In Practice Sessions and Segments...................60

Interobserver Reliability ........................................

Coaching Behaviors............................................ 63

Effects of the Coach's Verbal Interactions on Athlete Effort........67

Goal Orientation the Coach's Verbal Interactions Encouraged......71

Coach Provided Equitable Motivation to All Athletes..............73

Coach's Perception of His Behaviors............................. 74

Athlete's Perception of Their Coach's Behaviors.................77 
Chapter 5 Summary, Conclusions, and Recommendations

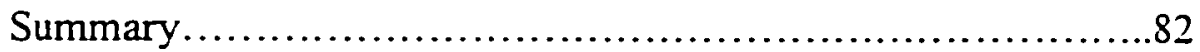

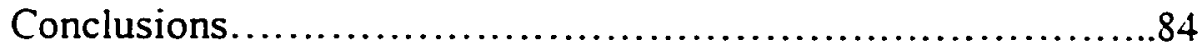

Practical Implications......................................... 86

Recommendations for Future Research...........................87

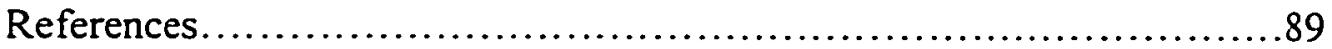

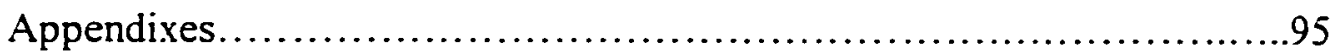

Appendix A, Smoll and Smith Model...........................97

Appendix B, TEOSQ .........................................99

Appendix C, CBAS ......................................101

Appendix D, Coach's Perception of Own Behavior ..............103

Appendix E, Player's Perception of Coach Questionnaire.........108

Appendix F, Informed Consent ..............................113 


\section{Chapter 1}

\section{Introduction}

"During the modern era, sport psychologists have studied the role of the coach as motivator, personologist, teacher of motor skills and strategist, but have largely ignored the important topic of leadership" (Straub, 1978, p. 381). "Despite four decades of empirical attention and the development of numerous theories, the status of leadership as an area of psychological inquiry is in some ways a promise unfulfilled" (Smoll \& Smith, 1989. p. 1522).

Coaching effectiveness is defined as "the behavioral process of influencing individuals and groups toward set goals" (Barrow, 1977, p. 232). This broad definition includes many dimensions of a coach's behavior: 1) decision making processes, 2) type and frequency of feedback given in response to an athlete's performance, 3) motivational techniques used and 4 ) the relationship with the athlete. Coaching effectiveness is "typically operationalized in terms of outcomes, that is, effective coaching is defined as that which results in: successful performance outcomes (win-loss percentages or degree of self perceived abilities) and/or positive psychological responses on part of the athletes (i.e., personal team satisfaction, coach-athlete compatibility)" (Horn, 1992, p. 181). A team's win-loss record may not be an adequate measure to use in the assessment of coaching effectiveness because win-loss records can be affected by many factors other than the coach's or the athlete's behavior. Therefore, coaching effectiveness should not be solely based on a team's win-loss record, but should also consider the psychological impact the coach has on the athletes. 
Coaching effectiveness research in sport is conducted under the general assumption that the type of leadership behavior exhibited by a coach will have a significant impact on the athlete's performance and/or on their psychological well-being (Smith, Smoll, \& Curtis, 1979; Smith, Zane, Smoll, \& Coppel, 1983). Coaching effectiveness has been studied for many years under various research methodologies. Between the 1930's and 1950's, the search for specific traits or behaviors common to leaders and coaches failed to identify a particular set of traits and behaviors that consistently discriminated between effective and noneffective leaders. This research found that there were, in fact, no particular set of traits that characterized effective coaches (Gould \& Weinberg, 1995; Horn, 1992). One major criticism with this type of research was the exclusive use of questionnaires or interviews (administered to administrators and others not directly involved in the sport) to determine coaching effectiveness. No data from the observation of the coach and athlete were considered or collected. Since that time, observation systems have been developed so that the behaviors of teachers and coaches can be observed, measured and analyzed.

There are two significant theoretical models that are currently used to study coaching/leadership effectiveness in sport. Chelladurai's Multidimensional Model of Leadership (1990), suggests that the congruence among a coach's behaviors, the preferences of the athletes, and the requirements of the situation have a positive effect on group performance and member satisfaction. Chelladurai's questionnaire, Leadership Scale for Sports (LSS), measures leadership behaviors, including athletes' preferences for specific behaviors, athletes' perceptions of their coach's behaviors, and coach's 
perceptions of their own behavior. The LSS has five components: training, democratic behavior, autocratic behavior, social support, and positive feedback. Chelladurai's model is situation specific. The model is based on research which shows that effective leadership is not universal across different situations. One problem associated with Chelladurai's model, with regard to its methodology, is the reliance on a questionnaire that may well measure the respondent's perceptions and attitudes, rather than the actual leadership behaviors of coaches (Smoll \& Smith, 1989). Even though the research completed during the 1930's through the 1950's also used this same type of methodology, current researchers have available the use of observation systems that allow observation and measurement of leadership behavior in naturalistic settings, rather than measure perceptions of behavior. Luthans (1979) emphasized that:

"One of the biggest problems with leadership research over the years has been the almost total void of observational measures of leadership behaviors in naturalistic settings. In our rush to respectability we have bypassed the widely recognized first stage of any scientific development-observation of naturally occurring events" (p. 205).

In contrast to Chelladurai, Smoll and Smith (1989) developed a model (Appendix A) which involved the assessment of a coach's behaviors through systematic observation, measurement of players' reactions to the coach through various questionnaires, and training the coach to modify their behavior through evaluation. The Coaching Behavioral Assessment System (CBAS) (Smith, Smoll, \& Hunt, 1977) was used to record and analyze behaviors in natural field settings. Two types of behaviors are recorded; one is a 
reactive response to a specific player and the second is a spontaneous response, which is initiated by the coach. The strength of Smoll and Smith's model is the use of various methodologies that allow for the collection of information on coaching behavior, rather than the reliance on a questionnaire.

The definition of coaching effectiveness has many components (i.e., decisionmaking processes, motivational techniques, relationships with players) that must be measured to give an accurate description of a coach's effectiveness. Smoll and Smith (1989) suggest that:

"The sheer number of personal and situational factors that must be taken into account, as well as the complexity of cognitive processes and social interactions that occur within the leadership setting, pose formidable challenges for researchers. Because of the diversity of leadership situations, the most fruitful approach may be to delimit the focus of the research and theory construction to more specific and well defined settings in which variables of interest can be more readily specified and measured" (p. 1522).

One such variable of coaching effectiveness is motivation of athletes. A limited number of studies have been conducted on the effects of a coach's behaviors on athletes' motivation (Black \& Weiss, 1991; Horn, 1985; Westre \& Weiss, 1991). Black and Weiss suggest that "not only are coaches actual or observed behaviors important for understanding motivational effects, athletes' perceptions of their coaches styles and interactions are strongly related to motivational factors" (p. 311). For example, Weiss and Friedrichs found that perceptions of coaches as engaging in more frequent rewarding 
and social support behaviors and as having a democratic coaching style were related to higher satisfaction levels in athletes. Despite the insightful findings from these previous research studies of coaching behaviors, relatively little research has been conducted concerning the influence of the coach on the self perceptions and motivation of sport participants.

One theory of motivation is achievement goal orientation (Ames, 1992; Nicholls, 1989). Achievement goal orientation, whether an athlete is task or ego oriented, has received considerable research in the classroom and is now beginning to be examined in sport. An ego orientation relates to whether or not an athlete is more concerned about winning and losing (outcomes) whereas a task orientation refers to skill improvement (process). Studies have shown that task oriented behaviors relate to increased participation, effort, and persistence. Duda (1992) suggested that if task involvement is so desirable from a motivational standpoint, the question remains to how teachers and coaches can create and maintain a task-involving sport situation for their athletes and/or students? One promising research direction requires the determination of the psychological impact of significant others (i.e., the coach) on goal orientation. To begin to address this issue, there is a need for applied studies that implement and test the practical implications of recent goal-related research in real-life sport settings (Duda, 1992).

According to Duda (1992), an excellent model (Appendix A) for such research is based on the work of Smith and Smoll (Smith, et al., 1977; Smith et al., 1983; Smoll \& Smith, 1984). As suggested by Chaumeton and Duda (1988), the behavioral guidelines 
for effective coaching developed by Smith et al. (1978) can be considered to be the building blocks for a task involving environment. This type of work provides sound theoretically based guidelines for the practitioner in terms of how to foster "equality of motivation" (Nicholls, 1989).

Chaumeton and Duda (1988) found that high school coaches positively reinforced and punished their athletes during competition based on performance outcome rather than the performance process more than coaches at a lower level (elementary, middle school) of competitive involvement. The more ego involving social reinforcement pattern exhibited by the high school coaches paralleled the greater emphasis on ego-involved goals (win/loss) reported by the high school athletes in contrast to the younger groups in the study. The direct relationship between coaches' behaviors and athletes' goal orientation, however, was not examined in the Chaumeton and Duda (1988) study. Piparo, Lewthwaite, and Hasbrook (1993) examined young athletes' perceptions of their coach's behaviors as potential predictors of their goal orientations. The results indicated that the more the coach encouraged mastery of skill and enjoyment the stronger the focus on mastery-related goals became among athletes. Athletes who perceived that their coach demanded a task focus tended to emphasize mastery and competitive achievement (ego involving) goals, although, Piparo et al. (1993) were not able to determine the actual behaviors of the gymnastics coaches. Taking the findings of this study and the work of Chaumeton and Duda (1988), the coach appears to play a significant role in shaping the adopted goal orientation of athletes. According to Duda (1993) more systematic research is needed that tests this possibility. 
In addition to advances in observation instruments designed to collect information about a coach's behavior, instruments have been developed that collect data on the behaviors of the athletes (i.e.. academic learning time, motor skill engagement). Academic Leaming Time in Physical Education (ALT-PE) was designed to determine the amount of time the athlete or student was appropriately engaged in the assigned task versus listening to instructions, waiting in line, or moving from one drill to another. Motor skill engagement (MSE), a construct, similar to ALT-PE is used to identify the specific amount of time the student or athlete is engaged in the activity successfully, not just engaged in the subject matter. Achievement motivation theory predicts that if one is task oriented, they will tend to be mastery oriented, and as a result will exert more effort, thus be on task and motor engaged appropriately in the task (Duda, 1993). Studies examining the behavioral correlates of dispositional goal perspectives have found the emphasis placed on task involved goals to positively relate to effort exerted and sustained involvement in athletic settings (Duda, 1993). Research on teacher effectiveness has recognized the importance of not only measuring teaching behaviors, but also measuring student behaviors as well. Although limited research has been conducted in this area in sport, this concept has also been applied in sport measuring athlete behavior (McKenzie, 1986).

"Just as studying student behaviors and achievement provides insight into effective teaching in physical education, the issue of how athletes spend their time in practices is important for understanding what constitutes coaching effectiveness. More research is needed to describe what athletes do in practice, to 
examine what the relationships of coaching behaviors is to the athlete's activities in practice, and to determine whether changes in coaching behaviors would change the practice behaviors in athletic practice sessions, particularly in motor skill engagement" (Lacy \& Martin, 1994, p. 97).

\section{Statement of the Problem}

Research examining the effects of coaching effectiveness on athlete psychological growth using systematic observation is very limited (Horn, 1992).

"Despite the widespread use of this type of instrumentation in the general education literature and, to a lesser extent, in the physical education literature to investigate teaching effectiveness, relatively few researchers in the sport psychology literature have employed such behaviorally based scales to assess coaching effectiveness relative to athletes psychological growth" (Hom, 1992, p. 192).

The few researchers who have completed studies have found that these scales can be used to discriminate between the effective and ineffective coaching behaviors in particular athletic settings (i.e., Horn, 1985; Smith et al., 1983; Smoll et al., 1978).

In general, most studies examining coaching effectiveness, except for the work completed by Smith and Smoll and associates, have concentrated solely on the use of one instrument (either systematic observation or a questionnaire) to understand the coach's behavior on the athletes. Horn (1992) stated that only through the use of diverse measurement systems (i.e., systematic observation as well as questionnaires) will a comprehensive understanding of coaching effectiveness be obtained. Few studies have 
assessed the effects of coaching behaviors on psychological development of collegiate athletes, yet fewer studies that examine athlete effort.

\section{Statement of the Purpose}

The primary purpose of the present study was to determine the effects of a coach's behaviors on athlete effort. The study was based on previous work completed by Smith et al. (1978), however instead of examining self-esteem and attitude of the athletes, the motivational orientation was examined as suggested by Duda (1992). The secondary purpose of the study was to determine, based on the coach's verbal interactions, which goal orientation(s) the coach encouraged and if the coach provided equitable motivation to all types of athletes (starter, nonstarter, task oriented, ego oriented). The tertiary purpose of the study was to determine how accurate the coach's perception and the athletes' perceptions of the coach's verbal interactions related to the actual verbal interactions with the athletes of differing status and goal orientation.

The present study was an extention of the study conducted by Chameton and Duda (1988) who examined task/ego orientations, coaches' behaviors, and the coaches' positive and negative interactions with regard to task/ego orientation. The present study extends past research by seeking to understand if the coach's verbal interactions differentially effect an athlete's effort with different ego and task orientations as well as between starter and non-starter athletes. This research should provide insight into Nicholl's (1989) concern for establishing empirically based guidelines for "equality of motivation". 


\section{Research Questions}

The following research questions were made for the purpose of this study:

1. What were the effects of the coach's verbal interactions on athlete effort?

2. What goal orientation(s) does the coach's interactions encourage?

3. Does the coach provide equitable motivation to all types of athletes (starter, nonstarter, task oriented, ego oriented)?

4. How accurate does the coach's perception of his verbal interactions relate to his actual verbal interactions with athletes of differing status and goal orientation?

5. How accurate do athlete's perceptions of their coach's verbal interactions relate to his actual verbal interactions with athletes of differing status and goal orientation?

\section{Assumptions}

1. The type of leadership behavior exhibited by a coach had an impact on the collegiate athlete's performance and/or on their psychological well being.

2. The athletes responded truthfully to the questionnaires.

3. The coach responded truthfully to the questionnaires.

4. The items in the instruments represented the differences between an effective and an ineffective coach.

\section{Delimitations}

1. The study was delimited to male collegiate soccer players who:

a. played on the Las Positas College Soccer Team during the 1997 season.

b. were over the age of 18 . 
2. The study was delimited to the coach who:
a. coached the 1997 Las Positas College Soccer Team,
b. was 50 years old,
c. had 20 years of coaching experience.

3. The study was delimited to verbal interactions of the coach only.

\section{Limitations}

1. The coach and the athletes did not change their behavior because they were being observed.

2. The subjects answered all questions on the questionnaires honestly.

3. The subjects were truthful about their perceptions of the coach and athletes.

4. The win/loss record for the season was not a significant influence on coach and athlete behavior.

5. Outside events (i.e., personal or family problems) did not influence motivation significantly.

\section{Definitions}

1. Coaching Effectiveness - "the behavioral process of influencing individual goals" (Barrow, 1977, p. 232).

2. Duration Recording - recording the elapsed time during which an event occurs.

3. Effort - motor skill engagement (MSE) - "the amount of time that players are appropriately motor engaged in activities (warm-up, drills, scrimmage, and conditioning) related to soccer during the practice session" (Lacy \& Martin, 1994, p. 97). 
4. Event Recording - An observational recording procedure in which one records the number of occurrences of a specified discrete behavior.

5. Motivation - "the direction and intensity of effort" (Gill, 1986).

6. Target athlete - the athlete who receives a verbal interaction from the coach. 


\section{Chapter 2}

\section{$\underline{\text { Review of Literature }}$}

Introduction

The following chapter reviews research that has been conducted using systematic observation methods. Systematic observation has been used in the classroom and in physical education as well as in sport. Systematic observation research that has been conducted in sport examining coaching effectiveness includes studies investigating the differences between successful and non-successful coaches and coaches' psychological effects on athletes. In addition, systematic observation has also been conducted on athletes to better understand the effects that coaches have on athletes' behavior. Achievement motivation is also reviewed along with studies that have examined achievement motivation in naturalistic settings.

Svstematic Observation in the Classroom and in Physical Education

Systematic observation, or direct observation, allows a person trained on the observation instrument to observe, record and analyze behaviors. It involves both observing and recording overt behavior and is done by coding each behavior into one or more categories. Systematic observation of behavior became popular in anthropology, social psychology, clinical psychology, and cross-cultural psychology (van der Mars, 1989). It has been used to aid professions in such areas as social work, psychology, rehabilitative medicine and education.

In the 1960's the use of systematic observation instruments became important in the study of classroom teaching. Since then, important variables have been found to 
contribute to student achievement and teacher effectiveness. From 1960 to 1970 numerous studies on teacher effectiveness were conducted that Rosenshine (1979) published the now famous report in which eight teacher variables were found to consistently correlate with student achievement. These variables were teacher clarity, variability, enthusiasm, task oriented or businesslike behavior, teacher indirectness, student opportunity to learn criterion materials, use of structuring comments, and criticism. Research efforts eventually began focusing on student behavior as well. Some student behaviors that were correlated to academic achievement included time on task, student engagement and academic learning time (ALT).

The use of systematic observation systems in the study of physical education and sport settings grew out of the classroom research agendas and numerous systematic observation systems emerged to study student and teacher behavior in the gymnasium. At about the same time Rushall and Siedentop (1972) applied Skinner's theories to physical education and sport in their pioneering book titled The Development and Control of Behavior in Sport and Physical Education. Their approach attempted to modify sport behavior by manipulation of the environment. This scientific approach according to Rushall and Siedentop could lead to principles of learning that would be applicable to teaching physical education and coaching sports. They emphasized only those behaviors that could be observed and measured systematically. They placed an emphasis on shaping the environment to bring about the desired response of athletes and students. 
In physical education, Siedentop (1991) used the same concepts that were used in classroom research and applied them to the study of physical education and teacher effectiveness. One example, academic learning time in physical education (ALT-PE), has received a considerable amount of attention. Other variables (i.e., motor skill engagement and opportunity to respond) have been used to help better understand the physical education environment and a great deal has been learned that would otherwise have been difficult to understand without the use of systematic observation (van der Mars, 1989). Systematic observation has played a major role in generating at least some of the answers regarding good or effective teaching over the past 20 years. More is known today about effective teaching than prior to the use of systematic observation techniques (van der Mars, 1989).

\section{Svstematic Observation of Coaching Behaviors}

One of the first studies that examined the relationship of behavior between coaches and athletes through systematic observation was conducted by Tharp and Gallimore (1976). Tharp and Gallimore (1976) observed John Wooden, former men's basketball coach at UCLA for 30 hours during practice sessions. They recorded over 2,300 of his behaviors using an 11 category coding system. They conducted the study to provide a description of a successful coach noted for his teaching ability that could be useful for educational practices in the classroom. Tharp and Gallimore (1976) found that about half of his communications with athletes were instructions (50.3\%), 17\% were "scolds" following misplays, $8 \%$ were complaints, and $7 \%$ were encouragement. 
Many systematic observation instruments have since been developed (Darst, Zakrajsek, \& Mancini, 1989) specifically to investigate coach behavior (Lacy \& Darst, 1984; Rushall, 1977; Smith, et al., 1977). Two texts have reported numerous research studies completed that used systematic observation (Martin \& Hrycaiko, 1983; Martin \& Lumsden, 1987). These studies have found positive results on coaching effectiveness using a behaviorist approach.

Behavioral coaching refers to the consistent application of the principles of applied behavioral psychology to the improvement and maintenance of athletic behavior. Behavior modification or applied behavior analysis is based on the contention that human behavior is shaped by its consequences. Applied behavior analysts have used basic behavioral principles (such as reinforcement, extinction, punishment) to develop: 1) strategies for analyzing behavior into small components, 2) instructional techniques for developing the component behavior, 3) reward and feedback strategies for strengthening and maintaining desirable behaviors, 4) motivational strategies for maximizing effort and persistence and 5) cognitive behavioral techniques for preparing for competitions (Martin \& Hrycaiko, 1983).

Systematic Observation of Coaching Behaviors of Successful and Non-Successful Coaches

A number of studies have been conducted on coaches in several sport settings at Arizona State University either using the Arizona State University Observation Instrument (ASUOI) (Lacy \& Darst, 1984) or a modified version of the instrument used by Tharp and Gallimore (1976). These studies were conducted to determine behavioral 
differences between successful and non-successful coaches based on winning percentages. These studies emphasized winning as the primary outcome of effective coaching, not the psychological impact the coach had on the athletes.

Williams (1978) used a modified version of the Tharp and Gallimore (1976) instrument to systematically observe a successful high school head basketball coach. Williams observed practices twice a week throughout the season and compared the results to Tharp and Gallimore's (1976) observations of former UCLA basketball coach John Wooden. Williams found that the high school basketball coach emphasized instruction, as did Wooden, however, used praise much more frequently than Wooden. Williams concluded that differences in maturity, skill level and motivation of the players at the high school and college levels could explain the differences in the use of praise.

Langsdorf (1979) used a modified version of the Tharp and Gallimore (1976) instrument to systematically observe Frank Kush, a highly successful Arizona State University head football coach. One purpose of the study was to compare Kush's behavior to John Wooden, a highly successful UCLA basketball coach. Langsdorf observed 18 spring practice sessions. Behaviors were analyzed according to the segment of the practice session in which they occurred. Different practice segments included warm-up, individual, group, scrimmage and conditioning. Random interobserver reliability checks were made on four occasions during the eighteen practice sessions. There was an $85 \%$ interobserver agreement. Percentages of behavior and behavior rates were calculated for each category. The study found that the greatest percentage of behavior for Kush occurred in the instructional category, followed by the hustle category, 
and the scold/reinstruction category. Praise was the fourth most frequent behavior observed for Kush, which was almost equal to the percentage of scolds. Kush's behavior varied according to the segment of the practice. The conditioning segment was high in hustles, the individual work segment was high in praise, and the scrimmage segment was high in the scold. There was a high correlation $(r=.85)$ between the behavior of Wooden and Kush. Differences between the two coaches were also reported. Although Kush had a higher percentage of the scold and praise statements, both coaches used praise and scold in approximately a $l: 1$ ratio. The percentage of instruction for Kush was approximately $15 \%$ less than it was for Wooden.

Langsdorf (1979) offered these implications for coaches, including: 1) coaches might benefit from training in providing instructions, 2) praise may not be as important a motivator at the college level as some other behaviors may be, including scolding, 3) scold statements may be most effective when they carry instructional information, 4) hustle behaviors seemed to be an effective way to generate enthusiasm during practice session and appears to help motivate players, and 5) the design of the practice session appears to affect the percentage and rate of behavior, since one's behavior may tend to vary from segment to segment.

Model (1983) systematically observed, analyzed, and described the coaching behavior of non-winning head varsity high school football coaches from the Phoenix, Arizona area and compared the findings to similar studies completed with winning coaches. Six coaches were observed using a twelve category systematic observation instrument. The instrument used event recording and interval recording procedures. 
Each coach was observed once during pre-season, early-mid season, and late season practice sessions, for a total of three observations per coach. Furthermore, the systematic observation system categorized each practice behavior for three levels including individual, group, and team.

Data showed that non-winning coaches exhibited behavior at a greater rate per minute during the pre-season phase than during the early-mid and late season phase. Non-winning coaches also engaged in significantly more instruction and positivemodeling during the pre-season than they did during the early-mid and late season practices. A greater percentage of instruction behaviors were exhibited and at a rate per minute greater than any other behavior. In fact, the instruction and other categories accounted for $70 \%$ of the total intervals recorded during practice. The non-winning coaches had a greater praise to scold ratio (4:1 compared to $1: 1$ in Langsdorf, 1979 and Williams, 1978) studies. The non winning coaches used hustle and scold less frequently than did winning coaches. There were high correlation's found between coaching behaviors of the non-winning coaches and the winning coaches in the four studies used for comparison, indicating that there are probably other factors that determine whether or not a coach has a winning record.

Lacy and Darst (1985) systematically observed and analyzed coaching behavior of 10 winning high school head football coaches in Phoenix, Arizona. Practice sessions were observed during three phases of the season: pre-season, early-season, and late season. Each coach was observed once in each phase. Observations were made during warm-up, group, team, and conditioning phases. The behavior was recorded in an 
eleven-category system, a modification of Tharp and Gallimore's (1976) instrument. Event recording was used for data collection, which is a cumulative record of the number of discrete events occurring within a specified time (Siedentop, 1991). Interobserver agreement checks were made for each phase of the season. An analysis of variance with repeated measures was used to statistically determine if significant differences existed at the .05 level between the various coaching behavior categories in the different phases of the season. The number of behaviors was totaled for each category of coaching bchavior. This was done to determine the percentage and RPM of total behaviors exhibited for the group of coaches for each practice segment and for each phase of the season.

The interobserver agreement for the preseason was $93 \%$, early season. $95.3 \%$, and the late season $98.4 \%$, with an entire season average interobserver agreement of $96.4 \%$. More behaviors were recorded in the preseason phase than in either of the other two phases. The rate per minute of behaviors was higher in the preseason $(5.31)$, than in either the early (3.70) or late season (3.67). None of the eleven percentages of behaviors were found to show any significant differences between phases. However, four of the 11 defined behavior categories showed a significant rate per minute difference between the preseason and the other two phases of the season. These were the categories of praise, scold, instruction, and positive modeling. No significant differences were found between the early and late season phases.

The increased amount of behavior found in the preseason indicated a more involved coaching style in the first part of the year since practices are usually focused more on basic fundamentals and individual skills. The group segment was used most in 
the preseason. During the early and late season, the team segment was used more frequently than the group segment. Across the season, praise was used more than twice as much as scold was. This finding that more can be accomplished by the coach using positive rather than negative interactions. The instructional category was used more than twice as often as any other behavior in every phase of the season. This finding is in agreement with past studies (Langsdorf, 1979; Tharp \& Gallimore, 1976; Williams, 1978) and supports the notion that informational feedback is essential for effective coaching.

Claxton (1988) described and systematically analyzed the coaching behavior of more and less successful high school boys' tennis coaches during practice sessions. Claxton used the ASUOI, which consisted of 14 behavior categories to systematically observe nine coaches, three times each during pre or early-season, mid-season and late season. Time sample event recording (Rushall, 1977) was used for each observation. Each observation consisted of three ten-minute periods spaced ten minutes apart for a total of 90 minutes per coach. Coaching behavior was recorded and reported in both rates per minute and percentage of total behaviors. This allowed a comparison to be made between the coaching behavior of tennis coaches with the coaching behaviors described in other studies conducted in different sports.

Instructional behaviors (20.1\%) were found to be the largest single category of coaching behaviors. The categories of management, silence and other made up $74.9 \%$ of all observed behaviors. The overall results showed that more and less successful tennis coaches were very similar in their use of most categories, less successful coaches gave 
post-instructional behaviors more than twice as often and praised almost twice as much as the more successful coaches. Less successful coaches also showed fewer other behaviors and questioned less than half as often as the more successful coaches. More and less effective tennis coaches were significantly different with regard to questioning. The more successful coaches asked more questions of their players than did the less successful coaches.

The boy's high school tennis coaches in this study spent a great deal of time in management, silence, and other behaviors that are recognized as low productive behaviors (Rushall, 1983). Consistent with other studies (Lacy \& Darst, 1985; Langsdorf, 1979; Tharp \& Gallimore, 1976), instruction was the most often exhibited behavior. One interesting finding was that the less successful tennis coaches instructed more than the more successful tennis coaches. Both this study and Model (1983) found that the less successful coaches used less praise than did the more successful coaches. The tennis coaches spent most of their time in the categories of silence, management, and other, which could indicate that the coaches were off task. However, Rushall (1983) has shown that coaches of different sports use different coaching behavior. Tennis players may benefit most when they are given time to practice rather than listening to instructions.

Segrave and Ciancio (1990) systematically observed coaching behaviors of a successful Pop Wamer football coach using the 11 -category observation instrument developed by Tharp and Gallimore (1976). The second purpose of the study was to compare the results with Tharp and Gallimore's (1976) study of John Wooden and 
Langsdorf's (1979) study of Frank Kush. Beau Kilmer was the subject selected for the study. Kilmer had an extensive coaching background and produced successful teams during his 18 years of coaching youth sport. Five observations were made during each phase of the season, which included a sample of behavior from preseason, early, mid, and late season. Thirteen behavior categories were used. The researchers also wrote field notes as a supplement to aid in data explanation and interpretation. A pilot study was conducted for training purposes and reliability of observer was determined. An independent observer made reliability checks on four occasions during the present study and all categories were found to have $80 \%$ or higher interobserver agreement.

Results showed that Kilmer's coaching was dominated by four types of behavior: instruction, coach interaction, praise, and "other", which accounted for $78.54 \%$ of all behavior. Overall, the most frequent behavior was instruction. Kilmer was very active in praising his players and creating a supportive environment. The praise to scold ratio was 2.5:1. Scolding behaviors consisted of only $10.76 \%$ of all behavior. Instruction, modeling-positive, and questioning showed a decrease and coach interaction and other showed an increase throughout the season. When comparing the coaching behavior of Kilmer and Kush, instruction ranked first of all coaching behaviors for both coaches. Both coaches also were similar in their use of modeling preferring to use a positive type modeling. These two characteristics were the only similarities between the two coaches. Kilmer demonstrated high levels of praise, questioning, and nonverbal rewards, whereas Kush demonstrated high levels of hustle, scold/instruction, scold, and nonverbal reward. 
The results from this study suggest that Kilmer tended to rely on positive behaviors to show support and encouragement, while Kush tended to use negative behaviors with his players. The explanation for these differences might be attributed to the age level the athlete coached. Kush coached college aged men, while Kilmer worked with younger boys. One other interesting finding was that Kilmer interacted with his assistant coaches more than Kush. The comparison between these two coaches and John Wooden showed that Wooden is much more like Kush than Kilmer. Pearson correlation's showed Kilmer to Wooden $(r=.37)$ to be more dissimilar compared to Kush and Wooden $(\mathrm{r}=.85)$. Kush and Wooden coach from a negative perspective, while Kilmer from a positive perspective to motivate players. Instruction was ranked first for all three coaches. Comparisons between these coaches indicated a differential use of coaching behavior dependent on the age and background of the athletes involved.

Lacy and Goldston (1990) systematically observed, analyzed and compared the behavior of five male and five female varsity girl's high school basketball coaches. Data were collected using the ASUOI. Each subject was observed three times during both preseason phase and inseason phase practice sessions. No data were collected during warm-up and/or conditioning parts of the practice session. Percentages and rate per minute were calculated for each behavior category. Interobserver agreement (96\%) was calculated prior to data collection. Subjects were chosen based on gender, past winning percentage, and years of experience.

The four most commonly used behaviors during the preseason for all coaches was instruction, post-instruction (19.4\%), concurrent instruction (19.2\%), management 
$(14.9 \%)$, and praise ( $11.8 \%)$. The praise to scold ratios for male and female coaches were approximately $2: 1$. The most common behavior used by female coaches was postinstruction (22.7\%) and the male coach's predominantly used concurrent instruction $(20.8 \%)$. Some other differences between the male and female coaches included that the male coaches exhibited a higher rate of pre-instruction (14.7\%), while the female coaches used this only $8.8 \%$ of the time. Also, female coaches used first names $(17.4 \%)$ considerably more than males $(9.2 \%)$.

The four most commonly used behaviors remained consistent between the inseason and preseason with the exception of concurrent instruction (20.0\%) which was ranked first and post-instruction (18.4\%) which was ranked second, followed by management $(15.8 \%)$, then praise $(11.7 \%)$. The most common behavior used by male coaches was concurrent instruction (21.8\%) and for female coaches was post-instruction (19.6\%). The biggest difference between male and female coaches during the inseason phase was in the management category, which for female coaches was $19.4 \%$ and for male coaches was $12.5 \%$. During this phase male coaches increased their use of first names, but female coaches decreased their use of first names compared to the preseason. The approximate $2: 1$ praise to scold ratio remained constant between phases.

Overall, throughout the total season the most common behavior used by both male and female coaches was concurrent instruction (19.6\%), followed by postinstruction (18.9\%). The most common behavior exhibited by female coaches was postinstruction (21.3\%), while for male coaches it was concurrent instruction $(21.2 \%)$. The praise to scold ratio overall exceeded a 2:1 ratio with the females coaches exhibiting 
slightly more praise than did the male coaches. The greatest differences between female and male coach behavior was the use of first names (females $14.9 \%$ to males $9.9 \%$ ), postinstruction (females $21.3 \%$ to males $16.6 \%$ ), management (females $17.6 \%$ to males $13.1 \%$ ), and pre-instruction (females $13.3 \%$ to females $8.9 \%$ ).

The results of the study showed that instruction (49.6\%) was the most common behavior observed by both the male and female coach. The second most common behavior was encouragement and the third major behavior was management. The three behaviors including instruction, encouragement, and management composed $83.4 \%$ of the total behavior for all subjects demonstrating that these were the coach's main functions. Female coaches used more first names when communicating with the players than the male coaches. Male coaches exhibited modeling and questioning behaviors more than the female coaches did.

\section{Systematic Observation of Coach and Athlete Behaviors}

Rushall (1983) used the Coach Observation Schedule (COS) (Rushall, 1977) to record coaching and teaching behaviors (positive and negative responses) in sports and physical education settings. Time spent in physical activity was also recorded for selected participants. These two observations sought to determine the development and control of physical activities. Observations were made for the sports of swimming, volleyball, and basketball as well as physical education classes. Rushall suggested that there is a necessity to evaluate the validity of systematic observations across various sports. The study was conducted to assess the assumption that general coaching behaviors are present across varying sports. 
Observations were conducted by the author and students from 1973 to 1979 in a variety of settings and levels $(N=30)$. Settings included in this study were the Canadian provinces of Ontario, Nova Scotia, Quebec and New Brunswick and the states of Connecticut, Maine, New York and Ohio in the United States. A "good" performer and a "poor" performer were selected to be observed for a one hour period of their participation, with the observer alternating between the two performers throughout the pre-determined time. A four minute observe, one minute record was used to document the percentage of time the subject was involved in physical activity. Physical activity was defined as any locomotion greater than a walk or the execution of an activity skill by a participant that occurred in training/class. Coaching behaviors were categorized into seven categories using the COS, with more of an emphasis on the positive and negative consequential responses. For both the $\operatorname{COS}$ and the physical activity observations, every third observation session, another observer was obtained to establish interobserver reliability. Interobserver reliability had to be $80 \%$ or greater for the data to be included.

The greatest number of observations with the highest percentage of participant physical activity occurred in swimming (70-80\%), followed by women's volleyball (30$40 \%)$. Physical education showed the lowest amount of physical activity $(10-20 \%)$. The consequential behaviors were found to be strongly negative for swimming, negative for physical education, while volleyball and basketball were found to be positive.

Overall, the findings indicated more differences than commonalties between the four physical activity environments. The differences in forms of behavior in each of the four activities suggested that each activity has specific behavior requirements by the 
teacher or coach. Rushall (1983) suggested the most effective behaviors for a coach to exhibit are high productive behaviors (positive and negative feedback). Results showed that there was a low occurrence of high productive behaviors in most of the activities observed in the study. Results also showed that the observational behaviors (monitoring and attending) were the most frequent behavior observed for all teachers and coaches.

Lacy and Martin (1994) conducted a study to measure coaching behaviors and motor skill engagement (MSE) between starter and nonstarter collegiate women's volleyball players during preseason practice sessions. In this study, MSE was defined as the amount of time that players were appropriately and successfully motor engaged in activities (warm-ups, drills, scrimmages, conditioning) related to volleyball during the practice session. Although much research has been completed on teaching behaviors and student activities in physical education classes only a limited number of studies have been conducted between coaches and athletes. "Just as studying student behaviors and achievement provides insight into effective teaching in physical education, the issue of how athletes spend their time in practices is important for understanding what constitutes coaching effectiveness. More research is needed to describe what athletes do in practice, to examine what the relationships of coaching behaviors is to the athlete's activities in practice, and to determine whether changes in coaching behaviors would change the practice behaviors in athletic practice sessions, particularly in motor skill engagement" (Lacy \& Martin, 1994, p. 97).

The subjects were players and coaches of eight women's collegiate volleyball teams. Practices were videotaped using a camcorder with a wireless microphone system. 
Practices were taped from the initiation of warm-up through the completion of the last drill. Segments of the practice were defined and coded as a warm-up, skill work, scrimmage, or conditioning. Using the videotapes, the behaviors of coaches were interval recorded using an expanded version of the ASUOI. Duration recording was used to collect data on the MSE for starters and nonstarters in the videotaped practice sessions. Head coaches submitted a list of starters and nonstarters, and players to be observed were then selected for each session. Four players ( 2 nonstarters and 2 starters) wore scrimmage vests to allow for coding MSE from the videotapes for each practice session. Different starters and nonstarters were selected for each practice session. Most teams had at least 12 players which allowed for all six starters and nonstarters to be identified and coded for MSE in one practice each.

Volleyball players spent $12.4 \%$ of their practice time in warm-up, $77.75 \%$ in skill work, $7.7 \%$ in scrimmage, and $2.2 \%$ in conditioning. Across all segments of the 24 practices, observed players were engaged in MSE for $31.1 \%$ of the observed time. Starters were engaged in MSE for $31.2 \%$ and nonstarters for $30.1 \%$ of the practice sessions. A two-way repeated measure ANOVA showed no significant differences in MSE between starters and nonstarters across the segments of the practice sessions.

Results of observed coaching behaviors found the single highest category for coaches was silence $(35.3 \%)$, followed by other (verbal behaviors that cannot be understood or that do not fit into any of the remaining defined categories), correction (10.7\%), concurrent instruction (10.2\%), pre-instruction $(9.4 \%)$, praise-skill $(6.8 \%)$, management $(6.4 \%)$. Following silence and other, the next four highest categories 
(correction, concurrent instruction, pre-instruction, and praise-skill) were all instructional in nature. All instructional categories accounted for $39.8 \%$ of observed intervals. This finding supports results of previous studies reporting high percentages of instruction (Lacy, 1989; Lacy \& Darst, 1985; Lacy \& Goldston, 1990; Langsdorf, 1979; Model, 1983; Rupert \& Buschner, 1989; Segrave \& Ciancio, 1990; Tharp \& Gallimore, 1976; Williams, 1978). The overall praise-to-scold ratio was almost 7:1. Results from other studies show a range in praise to scold ratio from 1:1 (Lansdorf, 1979; Tharp \& Gallimore, 1976) in collegiate settings to as high as $4: 1$ in a high school basketball setting (Williams, 1978). This study provided initial descriptive information about coaching behaviors and player MSE for preseason collegiate women's volleyball. Results of this study offer a starting point for future research on player behaviors in the athletic environment and add to the database of completed research on coaching behaviors. Future research should include behaviors of players and coaches in the other phases of the season (i.e., early season, late season, play-offs) as well as what players are doing when they are not engaged in MSE.

\section{Coaching Effectiveness: Psychological Affects of Coaching Behaviors}

Despite a significant number of studies that have examined successful and nonsuccessful coaches, research examining the psychological impact a coach has on an athlete using systematic observation is very limited (Horn, 1992). The few studies that have been completed have found that they can be used to discriminate between effective and ineffective coaching behavior in particular athletic settings (e.g., Horn, 1985; Smith et al., 1983; Smoll et al., 1978). 
Smoll, Smith, Curtis, and Hunt (1978) used the Coaching Behavioral Assessment System (CBAS) developed by Smith, Smoll, and Hunt (1977), to conduct a study to establish the relationships between coaching behavior and player variables based on their model (Smoll, et al., 1978). The model involved the measurement of coaching behavior, player perception and recall of these behaviors, and player's evaluative reactions to the coach and other aspects of their sport experience. Perception and recall of those behaviors was assumed to mediate player's evaluative reactions to the coach's behaviors. Youth sports have grown considerably in the last three decades. Estimates of children participating in youth sports is as high as 17 million (Martens, 1978). There is little disagreement that the relationship between a coach and a player can have a significant impact on the child's experience. Despite this growth, there has been little systematic observation of coaching behavior and how that influences their relationship with players. In addition to the lack of research examining a coach's behavior, there also exists a lack of research that deals with player's perceptions of their coach concerning the impact on a player's self-esteem and attitude (Smoll, et al., 1978).

The psychosocial developments of children participating in sport depend on the way in which the environment is structured and supervised. Children should have a positive experience in youth sport. The coach or adult supervisor can have the most impact on these experiences. It would appear useful then to implement strategies designed to change coaching attitudes, goals, and behaviors in ways that can have a positive effect. It is hypothesized that differences in a child's attitude toward trained versus untrained coaches would be most pronounced in low self-esteem athletes. 
Smoll et al. (1978) systematically observed 51 male Little League baseball coaches and 542 of their players during a total of 202 complete games. An average of 1,112 behaviors were coded for each coach during the season. At the end of the season, coaches completed a questionnaire assessing what they perceived were the behaviors they displayed during the season based on examples developed from the observations made of them. The players were then interviewed individually ard given a questionnaire to evaluate their coach's behavior and attitude. Canonical correlations were used to identify the basis for relationships between observed and perceived behaviors. A factor analysis was used to determine the structure of the behavioral categories and the factors on players' responses to the attitude items.

In their study, Smoll et al. (1978) determined what coaches were doing during the season, what they thought they had done, what the children thought the coaches had done, and how the children felt about the coach. The factor analysis identified three behavioral dimensions: supportiveness, instructiveness, and punitiveness. Players responded better to coaches who engaged in higher percentages of supportive and instructional behaviors and less to punitive behaviors. Another important finding was the degree of accuracy of leader self-perceptions. Correlations between CBAS observed behaviors and coach's ratings of how frequently they performed the behaviors were low and nonsignificant. The player's ratings on the same perceived behavior scale correlated much higher with the CBAS behaviors. The data suggest that coaches had limited awareness of how frequently they behaved in certain ways, and that the players are more accurate perceivers of coaching behaviors. General self-esteem was found to be a 
significant moderator of attitude responses to coaches. Children low in self-esteem responded more positively to a supportive or instructive coach. Coaching behaviors had the least impact on high self-esteem children.

Based on the canonical relationships found between coaching behaviors and player variables in their previous study (Smoll et al., 1978), Smith et al. (1979) studied the effect of a training package, including a variety of behavior-change techniques in an attempt to train Little League baseball coaches to more effectively relate with their players. The training package included verbal and written presentation of behavioral guidelines, modeling, and behavioral feedback.

Thirty-one Little League baseball coaches were randomly assigned to a training group or a non-training (control) group. The training group participated in a three-hour preseason program designed to help the coach relate more effectively to children. The training presented and modeled behavioral guidelines both verbally and in written materials that were based on evaluation of most of the same coaches in the Smoll et al., (1978) study. A written brochure was given to the coaches that contained suggestions for communicating effectively with players. To assess the effects of the program, the coaches in both the training and non-training groups were observed using the CBAS for four games during the season. Training and non-training groups were compared to CBAS data, players' perceptions of the coach's behavior, and player attitudes toward themselves, the coach, teammates, and the sport.

The results indicated that the training group had a significant and positive influence on observed and player-perceived behaviors. These results were also consistent 
with the coaching guidelines and with behavior-attitude relationships found in earlier research (Smoll et al., 1978). The coaches in the training group were also evaluated more positively by players. The children who played for the trained coach showed a significant increase in self-esteem as compared with results from a year earlier. The nontraining group did not demonstrate the same type of significant increase in self-esteem. Children with low self-esteem responded much better to the trained coaches as hypothesized by the researchers. The results of this study showed significant differences between the trained and non-trained groups, especially in the area of coach to athlete reinforcement. This study showed that coaches can be trained to communicate more effectively with their players and that self esteem an indicator of psychological impact can be influenced by a coach.

In a similar study, Smith et al. (1983) used systematic observation to observe the characteristics of coaching behavior during games. Included in this study were questionnaires designed to evaluate childrens' attitudes concerning the sport, their coach, their teammates and themselves. Also self-esteem of the athletes to determine relationships between coaches and athletes. Thirty-one youth basketball coaches and athletes were observed. Coaches ranged in age from 22-46 and had 0-16 years of coaching experience. Athletes ranged in age from 9-12 years. The CBAS was used to collect data from the coaches. The observers were male and female undergraduate students, who had been trained in the use of the CBAS. Data on frequencies and rates of specific coaching behaviors were collected. A factor analysis was used to determine the 
behaviors, and their relationship to children's post-season evaluation of the sport, the coach, and their teammates.

Nearly $75 \%$ of all coaching behaviors fell into three categories: reinforcement, general encouragement, and general technical instruction. Punitive responses made up only $6 \%$ of behaviors. Analyses of the player attitude scales suggested that generally children had positive attitudes toward the sport. There was a significant relationship between self-esteem and perceived team cohesion. Overall, there was a high correlation between observed coaching behaviors and post-season attitude toward sport and the coach. There was a low correlation between the rate positive reinforcement and any of the attitudinal measures. Punishment was a strong negative correlation to liking of the coach. In general, technical instruction was the strongest predictor of positive player attitude.

Chaumeton and Duda (1988) conducted a study to determine the differences in coaches' behaviors based on the situation (games vs. practices) and competitive level in relation to achievement motivation (task oriented and ego oriented goals). Nicholls' (1989) theoretical perspective are the assumptions concerning the psychological and behavioral consequences of task and ego orientation in achievement contexts which suggest that an emphasis on task oriented goals will tend to lead toward the exerting of maximal effort, good performance and continued participation. In competitive sport, the coach constitutes an important aspect of the social situation. Whether a coach creates a situation of greater or lesser social comparison and focuses on winning or skill improvement may influence the degree to which players adopt ego or task oriented goals. 
Smith and Smoll's (Smith et al., 1977; Smith, Smoll, Hunt, Curtis, \& Coppel 1978; Smith et al., 1983; Smoll \& Smith, 1980) research program has examined the possible effects of coaches' actions on Little League participants. Smith et al. (1978) observed explicit relationships between coaching behaviors and the perceptions and attitudes of the players. On the basis of these results, Smith et al. (1978) developed behavioral guidelines for coaches. In a later study, Smith et al. (1979) found that coaches trained to use the behaviural guidelines were liked better and rated as more effective teachers than other coaches. The effective coaching behavior guidelines developed by Smith et al. (1978) attempt to enhance player's motivation and self-esteem by encouraging coaches to de-emphasize the outcomes of players' actions, and stress the exerting of effort and mastery of specific abilities. Although a differentiation between task and ego oriented coaching behavior appears to be an important element in the guidelines, this distinction is not built into the CBAS (Smith et al., 1977). The CBAS only distinguishes between the reactive behaviors of positive and negative interactions in regard to desirable or undesirable performance in general.

The coaches of four elementary, four junior high, and four high school varsity boy's basketball teams were observed during two practices and two games using a modified version of the CBAS (Smith et al., 1977). The CBAS was modified to distinguish between coach's behaviors given in relation to the performance process or the performance outcome. Specifically, Chaumeton and Duda (1988) determined whether the positive or negative interactions of the coaches observed in this study focused on the performance process or the performance outcome. The relevant categories of behaviors 
coded during each competitive game and practice were re-categorized for the purpose of the analysis as being "desirable" (i.e., rewarding, encouraging) and "undesirable" (i.e., nonreinforcement, ignoring mistakes, punishing players). A MANOVA was calculated which analyzed for differences in the relative frequency with which coaches engaged in "desirable" and "undesirable" behaviors across situations and competitive levels. A MANOVA was also calculated which analyzed for differences in process oriented and outcome oriented behaviors across situations and competitive levels. During data collection, observers were placed in a position where they could observe coach-player interactions without disturbing the functioning of the team. In all situations, the coaches were aware of the presence of the observers but were unaware of the purpose of the study.

After the end of the competitive season, the players $(n=124)$ and coaches $(n=11)$ completed questionnaires designed and used by Smith and Smoll (Smith et al., 1978; Smoll \& Smith, 1984). The Coaches' Questionnaire consisted of two parts. In part one, the goals of the coaches were assessed by the Coach Philosophy Questionnaire in which eight reasons for taking part in the athletic program were matched with every other item in a 28 item forced choice format. Coaches were asked which of each pairs of goals was more important to them as a coach in regards to ego or task involved goals. Part two of the Coaches Questionnaire investigated the coaches' perceptions of their players' goals. Coaches indicated how important they perceived the task oriented goal (developing basketball skills) and the ego oriented goal (having a winning team) to be motivating their players to participate on the team and to try hard. The players' questionnaire 
assessed the emphasis placed on two major achievement goals in sport competition, the task oriented goal or the ego oriented goal.

Interrater reliability was found to be .903 (range $=.68$ to .96 across behavioral categories). Thus, the modifications made to the original CBAS did not appear to effect its reliability as a measure of coaching behavior. Significant differences were found between junior and high school varsity coaches' use of "desirable" and "undesirable" behaviors and high school varsity coaches' use of "desirable" and "undesirable" behaviors during practice and competition. High school coaches engaged in less desirable behaviors in competition than junior high coaches. In addition, high school coaches engaged in more undesirable behaviors in practice than in competitive sport. Significant differences were found between elementary and junior high and elementary and high school varsity coaches' use of these behaviors. Results indicated that there were significant differences between elementary and junior and high school varsity team coaches' use of process oriented and product oriented behaviors during practice and competition. Coaches of junior and high school varsity teams reinforced as a function of performance outcome more frequently during competitive situations than during practice. Coaches of elementary teams used process oriented behaviors more frequently than outcome-oriented behaviors less frequently than both junior and senior high coaches.

In regards to player's goals, a one-way analysis of variance indicated that at higher levels of competition winning becomes increasingly important. One way ANOVA's were performed to test for differences in the coaches' goals as a function of competitive level and also for the coaches' perceptions of the importance which athlete's 
place on having a winning team. Results showed significant competitive level differences between the importance, which coaches placed on creating a winning team. High school coaches valued winning more than junior high and elementary team coaches. Coaches perceived winning to be a more important goal to their players than did coaches of elementary and junior high teams.

In conclusion, the results revealed that the importance placed on outcomes of players' actions among coaches tends to increase with the level of competition. The differences in coaches' behaviors at higher competitive levels may have implications for the players. Their behaviors possibly create an environment, which could be detrimental to children who possess low self-esteem and effectively structure the context so that only children who possess high self-esteem can "survive". However, overall the great majority of coaches' behaviors at each competitive level (during both practice and competition) were exhibiting the behaviors which coach effectiveness guidelines (Smith et al., 1978) encourage coaches to use. The stated goals of players and coaches of teams competing at higher levels reflected a greater value on winning than did the players and coaches of teams competing at lower levels.

Piparo et al. (1993) examined young athletes' perceptions of their coach's behaviors as potential predictors of their goal orientations. Subjects were 200 competitive gymnasts between the ages of 9 and 14 years. Four coach behavior tendencies were considered: 1) provides encouragement for mastery and enjoyment, 2) demands a task focus, 3 ) is concerned about social relationships on the team, and 4) has a pressuring style. The results indicated that greater reported coach encouragement for 
mastery-related and enjoyment related to a stronger focus on mastery-related goals among athletes. Athletes who perceived that their coach demanded a task focus tended to emphasize mastery and competitive achievement (ego oriented) goals. Greater perceived use by a coach of a pressuring style was significant and negative predictor of mastery goal orientations.

\section{Achievement Motivation}

Recent motivation research stemming from a social cognitive perspective has focused on goal perspectives of motivational processes and behavioral patterns. A number of social cognitive theories have been proposed in an attempt to explain and predict behavioral variations in terms of the goals or motivational orientations of individuals (Duda, 1993). The theories have been primarily examined in academic achievement, but recent research and theoretical building indicate that these theories may also be applicable to the physical domain, including sport. Models of achievement motivation have been based on the theoretical contributions of Nicholls (1989), Dweck (1986), and Ames (1992). Although each theory has his/her preferred terminology, issues of emphasis, and conceptual suggestions, each of these theories have a number of common themes with respect to the conception and role of goals in motivation (Duda, 1992). In general these theories argue that a major focus in achievement settings is to demonstrate competence. Further, the psychological prominence of perceived ability is held to be the distinguishing factor of achievement motivation.

Social cognitive approaches to achievement motivation assume that there are two major goal perspectives operating in achievement contexts, task and ego orientations 
(Nicholls, 1989). These two goal perspectives relate to the ways in which individuals judge their level of competence. Consistent with other theories of achievement motivation, perceptions of competence are held to the primary focus and determinant of achievement attempts (Duda, 1993). Task oriented behavior focuses on the process, rather than the outcome of involvement in achievement situations. Skill improvement, task mastery, working hard, and active engagement in the activity are fundamental to perceived goal accomplishment when one is task-oriented. Examples of task oriented goals in sport include attempts to improve personal performance standards or to perform a skill in a technically correct manner. The criteria against which such performances are evaluated are inherent to the task itself or based on previous individual performances, rather than the performances of others. Success defined in these terms is experienced as intrinsic motivation derived from the mastery of the task itself (Weiss \& Chaumeton, 1992). In ego orientation, emphasis is placed on demonstrating superior competence and perceived ability is normatively referenced. Improvement and/or personal mastery is not enough to occasion feelings of high ability. In addition, success is dependent on a favorable comparison of one's own ability and with that of others (Duda, 1992). For someone who is ego oriented, the source of subjective success would be beating others with less effort in competition.

Recent social cognitive theories of achievement motivation (Ames, 1992; Dweck, 1986; Nicholls, 1989) affirm that that there are important interrelationships between goal perspectives, perceived ability, and behavior (Duda, 1992). Specifically, it is argued that the adoption of task oriented goals will lead to a strong work ethic, optimal performance 
(given the actual capabilities of the individual), and persistence. Task orientation should also correspond to the selection of competitive levels, opponents, and tasks that are conducive to maximal improvement and personal satisfaction, that is, those that are moderately challenging. Importantly, this positive behavioral pattern is predicted when people are task oriented, regardless of their level of perceived competence and is assumed to relate to the choosing of moderately challenging tasks, the exerting of effort, intrinsic interest in the activity, sustained or improved performance, and persistence. Further, due to the concern with personal skill development and the task at hand, task orientation should enhance the probability that individuals feel competent when engaged in achievement activities. In short, it is assumed that a task oriented goal perspective establishes the basis for maximal motivation and adaptive behaviors.

Because comparative judgments concerning one's own demonstrated ability (and exerted effort) to that of others underlies subjective success, maintaining a sense of high competence is much less secure when ego orientation prevails. If an individual is ego oriented and some question about his/her level of competence exists, a low-achievementoriented behavioral pattern is expected. Such individuals are more likely to reduce their effort, stop trying, or claim a lack of interest when compared to task oriented participants or those who are ego-oriented and confident of their abilities. When someone is ego oriented and low in perceived competence, she/he is predicted to choose the extremes in terms of the perceived challenge of the activity (i.e., either an opponent or task that is too difficult or too easy). Performance impairment and dropping out are also assumed to be behavioral consequences of ego orientation when the adequacy of one's ability is in 
doubt. Although this behavioral pattern is rational if the goal is to "save face" and preserve one's sense of superior competence, such behaviors are obviously maladaptive from an achievement standpoint (Duda, 1993).

Recent social cognitive theories of achievement motivation hold that situational factors and individual differences affect which goal perspective state predominates. In regard to the former, achievement environments vary in terms of the goal structure emphasized. When environments are marked by interpersonal competition, social evaluation and normative-based testing and feedback, ego orientation is more likely to result. Situations characterized by an emphasis on learning from one's mistakes, personal skill mastery, the importance of exerting effort, and participation for participation's sake tends to lead to task orientation. As suggested by Nicholls (1989), individual differences in dispositional goal orientation are a consequence of socialization experiences within the achievement domain. Interactions with significant others who reinforce a particular goal perspective and continued involvement in environments that manifest a particular motivational climate are believed to result in a tendency for task and ego orientation. Results from recent research (Duda, 1988) have demonstrated a consistent pattern of results. Individuals who participate in sport most extensively and who persist longest, appear to be both highly ego oriented and highly task oriented. Persons who are highly ego oriented but low on task orientation tend not to persist in sport for as long as those who are high in both goal orientations. In terms of behavioral intensity, the research to date has revealed a positive relationship between task orientation and exerted effort (Duda, 1988). These studies have provided initial support suggesting that social 
cognitive theories of academic achievement have relevance for the study of behavioral patterns in sport. This research has set the stage for more systematic, experimental research in the laboratory and in the field.

\section{Studies Examining Achievement Motivation in Sport}

Burton (1989) conducted a quasi-field experiment determining the effect of a 5month goal-setting program on perceived ability, perceptions of success, and performance. The goal setting program was targeted toward teaching the athletes how to set accurate, performance focused goals and downplay the significance of outcome goals. Performance goals were based on individual mastery and personal improvement with respect to technique and swimming times. In contrast to a control group of intercollegiate swimmers that did not take part in the program, program participants had higher perceived ability and perceived greater post competition success. Further, those trained swimmers who tended to set accurate goals exhibited higher performance than swimmers who focused on less accurate goals or members of the control group.

Duda and White (1992) determined whether similar goal-belief dimensions would generalize to a high-level competitive sport situation. Male and female intercollegiate skiers $(\mathrm{N}=143)$ indicated their agreement with a variety of reasons why someone would do well in competitive skiing. Factor analysis revealed four perceived beliefs concerning the causes of skiing success, namely effort (e.g., "athletes succeed if they work really hard"), ability (e.g., "athletes succeed if they are better athletes that the others"), external factors (e.g., "athletes succeed if they have the right equipment"), and illegal advantage (e.g., "athletes succeed if they do blood doping"). 
Elite skiers who were high in ego orientation tended to perceive that taking an illegal advantage, having the ability, and external factors lead to competitive success. Aligned with previous findings in sport (Duda \& Nicholls, 1992; Hom, Duda, \& Miller, 1993), task orientation positively related to the belief that achievement in skiing is a consequence of hard work and practice. In contrast to classroom-based studies a previous sport research, however, a strong task orientation was also associated with the opinion that possessing high ability results in success.

At this level of sport involvement, athletes believe that individuals must have high ability to be successful. Ego oriented athletes, though, tended to perceive that securing achievement required more than talent. In their view, factors outside oneself (like luck or equipment) and the engaging in illicit means were determinants of success in competitive skiing. Further, the value of working hard in terms of skiing success was overlooked among high ego-orientation skiers. Task oriented elite skiers, on the other hand, deemed ability and hard work as necessary ingredients for achievement.

Thus within the ranks of elite sport competitors, the results of the Duda and White (1992) study suggest that personal goals are compatible with how elite athletes view the causes of successful goal accomplishment. The task oriented conception of skiing success that emerged should be conducive to maximal motivation and sustained involvement in the sport of skiing. In contrast, the ego oriented theory of skiing achievement (in which ability and external factors, not effort, are deemed necessary for success) might present motivational problems in the long term for elite athletes. This would especially be true in the case of those intercollegiate skiers who doubt their 
competence. Further, since the ego oriented goal-belief dimension reflected the viewpoint that illegal and potentially harmful tactics will lead to success, this motivational orientation should be questioned on the basis of both health-related and ethical concerns.

\section{$\underline{\text { Summary }}$}

Currently there are two theoretical models examining coach effectiveness (Smoll \& Smith, 1989; Chelladurai, 1990) as it pertains to the athlete's psychological growth. A database is beginning to develop that examines differences between successful and nonsuccessful coaches based on winning records. Research examining the effects of coaching effectiveness on athlete psychological growth using systematic observation is very limited (Horn, 1992). "Despite the widespread use of this type of instrumentation in the general education literature and, to a lesser extent, in the physical education literature to investigate teaching effectiveness, relatively few researchers in the sport psychology literature have employed such behaviorally based scales to assess coaching effectiveness relative to athletes psychological growth" (Horn, 1992, p. 192). The few who have done so have found that these scales can be used to discriminate between the effective and ineffective coaching behaviors in particular athletic settings (i.e., Horn, 1985; Smith et al., 1983; Smoll et al., 1978). Smoll and Smith (1989) further state that "one of the biggest problems with leadership research over the years has been the almost total void of observational measures of leadership behaviors in naturalistic settings" (p. 1522). 


\section{Chapter 3}

\section{Methods}

\section{Introduction}

Many researchers have observed coaches' behaviors to assess coaching effectiveness in a variety of sports and competitive levels (i.e., Horn, 1985; Lacy \& Darst, 1985; Rushall, 1983; Smoll et al., 1978; Tharp \& Gallimore, 1976) using systematic observation instruments (Lacy \& Darst, 1984; Rushall, 1977; Smith et al., 1977). Limited research has been conducted observing coaching effectiveness relative to the psychological impact on athletes (Hom, 1985; Smith et al., 1983; Smoll et al., 1978), specifically goal orientation. In addition, limited research has been conducted observing athlete's behaviors (Lacy \& Martin, 1994; McKenzie, 1986; van der Mars, Darst, \& Sariscsany, 1991) and coach, athlete interactions (Mancini \& Wuest, 1987; Wuest, Mancini, van der Mars, Terillion, 1986;). Further, most research has been conducted on youth sport participants when examining athlete's psychological affects with few research studies focusing on collegiate athletes. The primary purpose of the present study was to determine the effects of a coach's behaviors on athletes' effort.

With regard to methodology, most studies on coaching effectiveness have either used only paper and pencil tests or only systematic observation instruments. With the exception of Smoll \& Smith's (Smith et al., 1979; Smith, et al., 1983; Smoll et al., 1978) work, no studies have attempted to use a combination of these instruments within the same study. Smoll \& Smith's model (1989) emphasizes that information on coaching effectiveness should come from a variety of sources including observation of a coach's 
behavior, athlete's perceptions of the coach, and the coach's perceptions of his own behavior. Horn (1992) further suggested that it is only through the use of various instruments that coaching effectiveness will be more fully understood.

Although systematic observation is an effective way to accurately record a coach's behavior, it can not ascertain information on attitudes, feelings, or thoughts. This information can best be ascertained by asking questions to the coach and athlete using a questionnaire or interview. Relying only on a questionnaire, on the other hand, does not allow for observation of natural occurring events that take place in a sport setting with a coach and athletes. This study systematically observed a coach's behaviors and gained insight into the perceptions of the coaches and athletes using various questionnaires related to coaching effectiveness and goal orientation.

\section{$\underline{\text { Subjects }}$}

Twenty-five collegiate male soccer players and their coach served as subjects in the study. The players were over the age of 18 . The coach was a 50 year old male and was in his 22 nd year of coaching soccer, having played soccer for a total of 45 years. The coach competed at the college level in many other sports in addition to soccer, which included football, track and field, and wrestling. The coach also had experience in coaching women at the collegiate level.

\section{Apparatus}

A camcorder with a wireless microphone system was used to record practice behaviors of the coach and the athletes. The camcorder was placed along the sideline of the soccer field captured athlete performance and coach interaction with target athletes. 
The researcher wore an ear jack attached to the camcorder in order to hear clearly the athlete's names used by the coach during his verbal interactions.

$\underline{\text { Instruments }}$

During the pre-season, Duda and Nicholl's (1991) Task and Ego Orientation in Sport Questionnaire (TEOSQ) (Appendix B) was used to assess each athlete's preference for task and ego goal orientations. When completing the questionnaire, subjects were requested to think of when they have personally felt successful in sport and then indicate their agreement with 13 items reflecting a task orientation (e.g., "I learn a new skill by trying hard") and ego orientation (e.g., "The others can't do as well as me"). Responses were evaluated based on a five-point Likert scale with the anchorings strongly agree to strongly disagree. The TEOSQ is a modified, sport-specific version of an inventory developed by Nicholls (1989) and his colleagues to assess task and ego orientation in an academic classroom environment. The results of the pretest provided the researcher with the type of goal orientation appropriate for each athlete.

The TEOSQ has an alpha internal consistency coefficient of .82 (Task orientation) and .89 (Ego orientation) for female and male high school varsity basketball athletes. Among other sports, alpha coefficients of .62 and .85 have been reported for the Task and Ego orientation subscales, respectively.

Principal component factor analyses support the construct validity of the TEOSQ. Duda (1989) has shown the TEOSQ to be concurrently valid by correlating athlete's responses to a Purpose of Sport Questionnaire. Task oriented athletes are characterized by mastery/cooperation, active physical lifestyle, and good citizenship. In contrast, 
athlete's responses to the Ego orientation subscale were positively correlated with the competitiveness, high status career, and social status/getting ahead subscales of the Purpose of Sport Questionnaire (Duda, 1989).

\section{Observation of the Coach: CBAS}

Chaumeton and Duda (1988) modified the 12 category CBAS (Coaching

Behavioral Assessment System) developed by Smith et al. (1977) (see Appendix C). The modified version of the CBAS was used to code the coach's verbal behavior throughout this study. The modifications to the original form of the CBAS differentiated between both positive and negative reactive behaviors directed at the processes (task orientation) and outcomes (ego orientation) of target athlete's behaviors. The revised behavioral categories were operationalized as follows: 1) Reinforcement for desirable outcomes - A positive verbal rewarding reaction, which is directed at a desirable outcome; 2) Reinforcement for desirable processes including effort - A positive verbal rewarding reaction, for a behavior directed at the process of the behavior (including effort); 3 ) Punishment for undesirable outcomes - A negative verbal reaction, which is directed at an undesirable outcome; 4) Verbal punishment for undesirable process or lack of effort. In addition, two behaviors of the 12 category CBAS were not used in this study. Nonreinforcement and Ignoring Mistakes have been found difficult to code (Smith et al., 1983) and since the videotaping will be focused on the athletes these two behaviors would be difficult to assess.

The CBAS system allowed observation of the basic interactions between the coach and the target athlete. Use of the observation instrument in observing and coding 
coaching behaviors in a variety of sports has indicated that the scoring system is sufficiently comprehensive to incorporate the vast majority of overt leader behaviors, that allow for high interrater reliability, and yet allow for individual differences in behavioral patterns that can be discerned (Chaumeton \& Duda, 1988).

\section{Observation of the Athlete: MSE}

To make inferences about effort, duration recording was used to collect data on the motor skill engagement (MSE) of starters and nonstarters as a function of the coach's interaction. MSE data was a reflection of the percentage of time an athlete was engaged appropriately in the motor skill (effort).

\section{Athlete and Coach Perceptions of Coaching Behaviors}

After the conclusion of the competitive season, the coach and athletes completed their respective perception questionnaire (Appendix D and Appendix E). Each questionnaire was designed and used by Smith and Smoll (Smith et al., 1978; Smoll \& Smith, 1984). One questionnaire was designed for the coach and a separate but similar questionnaire has been designed for the athletes to determine how each perceives themselves to statements on the questionnaire.

\section{Procedures}

Prior to any data collection, the coach introduced the researcher to the team. This was done to diminish the effects of the researcher's presence on changing athletes' behaviors. All athletes and the coach completed the informed consent (Appendix F). The athletes were informed that the study was designed to observe the coach and athletes 
during practice settings. The specific purpose of the study was not disclosed to either the coach or the athletes until the study had been completed.

To assure that the data collection period provided as accurate as possible information, decreased the possibility of technical problems, and researcher interference, a pilot project began on July 27, 1997 contingent upon Human Subjects Review Board approval. On July 27, 1997 through August 26, 1997 the researcher conducted videotaping of the off-season pericd of practice prior to the official start of the soccer season. The researcher videotaped athletes once a week for 4 weeks during this time period. Any adjustments to the data collection procedures or technology resulted at this point. In addition, all coding sheets associated with the data collection were completed after videotaping. This provided the researcher with practice in coding athlete and coach behavior.

After the pilot project was completed two graduate students were trained to use the CBAS and the MSE instruments. Since the researcher coded all CBAS and MSE for this study directly from the videotape it was essential that interobserver agreement (IOA) checks be calculated on the researcher's data. In addition, a practice videotape used from the pilot project was coded by the researcher as well as the graduate students to determine the percentage of IOA. IOA procedures served to check the reliability of the observations made by the researcher and eliminated or diminished researcher bias in the use of the observation instruments. IOA was determined by the following formula (van der Mars, 1989): 
Agreements

Agreements
Agreements + disagreements

If an IOA of $85 \%$ or higher was achieved, data was assumed to be valid and reliable.

On or about August 15, 1997 all athletes were pretested on their task and ego goal orientations using the TEOSQ (Duda \& Nicholls, 1991). Although the coach submitted a list of starters and nonstarters at a later date having knowledge of the athlete's goal orientation was important to know prior to the coach's input so that videotaping could commence on August 27, 1997. At a time more proximal to the competitive season, the coach conveyed to the researcher, starters and nonstarters. At which point both levels of athlete variables (starter, nonstarter, task oriented, ego oriented) were known. There were two variables, orientation and status, each having two levels. Athletes were categorized into one of the four groups based on the two levels of each attribute variable: their goal orientation (task/ego) and status (starter/nonstarter). The four groups were: 1) Starter/Task (ST), 2) Starter/Ego (SE), 3) Nonstarter/Task (NST), and 4) Nonstarter/Ego orientation (NSE). A hypothetical example of the athletes in each of the four categories is provided in Figure 1.

Horn (1992) suggested that to obtain an accurate measure of the behaviors between certain types of feedback and player's performance and/or psychological growth, researchers will have to record the coach's interaction's with an individual athlete rather than "without reference to the recipient" (p. 193). Research has demonstrated that coaches do not exhibit the same behaviors or provide the same type of feedback to all athletes on the team. For example, several research studies have found 
Athlete

Orientation

Athlete

Status

Task Ego

\begin{tabular}{|c|c|c|}
\hline Starter & $\begin{array}{l}\text { A1, A2 A5, A7, A8, } \\
\text { ST } \\
\text { A13, A21 }\end{array}$ & $\begin{array}{l}\text { A4, A11, A16, A17, } \\
\text { SE } \\
\text { A20 }\end{array}$ \\
\hline Nonstarter & $\begin{array}{l}\mathrm{A} 3, \mathrm{~A} 9, \mathrm{~A} 10, \mathrm{Al4}, \\
\text { NST } \\
\mathrm{A} 15, \mathrm{~A} 22\end{array}$ & $\begin{array}{l}\text { A6, A12, A18, A19, } \\
\text { NSE } \\
\text { A23, A24 }\end{array}$ \\
\hline
\end{tabular}

Figure 1. Hypothetical example of athlete's using the two factors (goal orientation and status).

that coaches give different forms of feedback to their high and low skilled athletes (Horn, 1985; Rejeski et al., 1979) or their starters and nonstarters (Markland \& Martinek, 1988).

Given this, players were videotaped at each practice session based on the verbal interaction of the coach to each athlete. The practices were videotaped from the initiation of warm-up through the completion of the practice session. The component parts of the observed practice were defined and coded as particular practice segments as outlined by Lacy and Martin (1994). The definition of these segments were: 1) Warm-up (any activity not using a soccer ball at the start of practice, such as stretching, calisthenics, to physiologically prepare for the practice), 2) Skill work (any drill the purpose of which is 
to develop a particular skill or group of skills necessary for game play), 3) Scrimmageany game situation play), and 4) Conditioning (activity with the sole purpose of increasing the level of physical fitness in such areas as strength, endurance, aerobic activity, or flexibility. Lacy and Darst (1985) have shown that observation of coach's behavior varies as a function of the segment of practice (e.g., warm-up activities, conditioning activities, group work, and team work) therefore each segment of practice was viewed separately and in combination with any other segment, as well as viewed as a total practice session.

A target athlete was defined in this study as the athlete who received a verbal interaction from the coach. The coach was instructed to use the name of each athlete when giving feedback. Once the coach verbally interacted with an athlete continuous duration recording was used to collect data on the MSE for that target athlete. The coach's verbal interaction and the resulting MSE were videotaped concurrently. The researcher had an ear jack attached to the video camera with a remote microphone attached to the coach's collar or shirt. Using a modified version of the CBAS (Chaumeton \& Duda, 1988) that includes verbal interaction categories only, observations of the coach were conducted throughout the practice session using a timeline coding sheet.

The telephoto lens focused on the target athlete in clear view to observe the athlete's motor skill engagement. Each target athlete was videotaped until the athlete's performance, with regard to the coach's verbal interaction, came to a natural conclusion. At that time the camera provided a wide angle view of the team awaiting the next coach 
verbal interaction in which the process for videotaping a subsequent target athlete commenced. Each of the athletes were observed based on the coach's verbal interactions throughout the entire practice, alternating between the athletes based on the coach's verbal interactions.

The videotape of each practice was coded by the researcher using a coding sheet. As the videotape was viewed, events were delineated on the coding timeline. The CBAS category used as the coach's verbal interaction was noted first. The researcher noted the use of the athlete's name and located the timeline for that athlete. At the point that the coach interacted, a symbol representing the type of interaction was placed in the coding timeline (RT, RE, PT, PE) at the time of the interaction. At that time the videotape displayed a close view of the target athlete. The researcher then calculated the amount of time athletes were appropriately and inappropriately engaged in MSE. At the natural conclusion of that particular activity, the videotape showed the entire team awaiting the next coach verbal interaction. This timeline brought together multiple sources of data, which provided a thick description of the interaction of the coach and his effect on athlete's MSE.

Data for the MSE time for each athlete was quantified and transferred to the tally sheet in order to calculate total minutes of MSE for each practice segment as defined previously, as well as for the total practice for each day and for the season. From this data the percentage of MSE for ST, SE, NST, NSE in the various practice segments and in the entire practice was calculated. Comparisons were then made as to the differential 
effects a coach's verbal interactions have on the effort demonstrated by different types of athletes (ST, SE, NST, NSE).

Since there is also a need to conduct multiple observations throughout the entire season (preseason, early season, mid season, and late season) (Lacy \& Darst, 1985), videotaping of athletes and coach occurred once a week throughout the entire season. The early season phase was August 18 through August 28, the mid season phase was September 4 through September 23, the late season phase October 2 through October 30 . There were a total of 12 practice sessions filmed. During the early season, practice sessions filmed included, August 18, 25, and 28, during the mid season included, September 4, 9, 18, 23, and during the late season included, October 2, 9, 16, 23, 30. Given that the number of available practice days varied depending upon the time in the season, the observation days were randomly selected each week from the available days for practice that week. Consultation with the coach provided the information necessary to make the randomized selection.

After the conclusion of the competitive season, the coach completed the coach's perception of his behaviors questionnaire (Appendix E). Athletes completed the players' perception of the coach's behaviors questionnaire (Appendix F). The coach was not present at the time the questionnaires were completed by the athletes. The questionnaires were completed in one of the college classrooms for ease and comfort. The players were assured that the coach would not receive any information regarding player's responses. Any and all information concerning an athlete was referred to as $\mathrm{A} 1, \mathrm{~A} 2, \mathrm{~A} 3$, etc. No reference was made to an athlete's name or position. Each athlete chose a personal code 
to use on the questionnaire with their name so that questionnaire's could be compared with the coach's verbal interactions and athlete behaviors.

Data Analysis

Means and standard deviations for each practice day and for each segment of the season were presented for each athlete and for each athlete group for CBAS and MSE data. 


\section{Chapter 4}

\section{$\underline{\text { Results and Discussion }}$}

Results of the data analysis are presented in this chapter. These results address the three purposes of the study. The primary purpose of the study was to determine the effects of a coach's verbal interactions on athlete effort as measured by motor skill engagement. The secondary purpose of the study was to determine, based on the coach's verbal interactions, which goal orientation(s) the coach encouraged and if the coach provided equitable motivation to all types of athletes (starter, nonstarter, task oriented, ego oriented). The tertiary purpose of the study was to determine how accurate the coach's perception and the athletes' perceptions of the coach's verbal interactions related to the actual verbal interactions with the athletes of differing status and goal orientation.

For the purposes of the analysis, data were reported for one coach and 25 athletes who finished the season. In addition, since only one athlete was determined by the TEOSQ (Duda \& Nicholls, 1991) to be ego oriented data were eliminated in the analysis for this athlete.

\section{Athlete Goal Orientation and Status}

Based on the TEOSQ, the athletes were found to be primarily task oriented. Twenty-four of the 25 athletes were task oriented. Task orientation scores ranged from 3.57 to $5(\underline{\mathrm{M}}=4.54, \underline{\mathrm{SD}}=0.38)$. Scores for ego orientation ranged from 1.33 to 4.67 ( $\underline{\mathrm{M}}$ $=2.77, \underline{\mathrm{SD}}=0.99$ ). These results are consistent with previous studies that have also used the TEOSQ (Duda, 1988; Duda, 1989; Duda \& White, 1992). Of the 25 athletes, 14 were identified by the coach as starters and 11 were identified as nonstarters. Of the 14 
starters, 13 were found to be task oriented and one was found to be ego oriented. All 11 nonstarters were task oriented. There were no changes in the athletes' status from starter to nonstarter throughout the season.

Time Spent In Practice Sessions and Segments

A total of 10 practice sessions (three early-season, three mid-season, four lateseason) were observed. Of the 12 practice sessions filmed, two of the videotapes (September 23 and October 30) were unable to be coded due to difficulties related to the technology of the video equipment. These two tapes were eliminated from the study. A total of $795 \min 9 \mathrm{~s}$ were observed during the 10 practice sessions (see Table 1). Of the total practice minutes observed, $36 \mathrm{~min} 45 \mathrm{~s}(4.50 \%)$ were spent in warm-up, $138 \mathrm{~min}$ $50 \mathrm{~s}(17.48 \%)$ in drills, $472 \mathrm{~min} 43 \mathrm{~s}(59.37 \%)$ in scrimmage, $58 \mathrm{~min} 37 \mathrm{~s}(7.30 \%)$ in conditioning, and $41 \mathrm{~min} 24 \mathrm{~s}(5.16 \%)$ in instruction. The mean length of the practice sessions was $79 \min 30 \mathrm{~s}(\underline{\mathrm{SD}}=18 \mathrm{~min} 9 \mathrm{~s})$. The scrimmage was the only segment of practice used during each of the 10 observed practice sessions. The conditioning segment was included in nine practice sessions, the drill segment was included in eight practice sessions, and the conditioning segment was included in seven practice sessions. The warm-up segment was included in only five out of the 10 practice sessions.

The scrimmage constituted the greatest percentage of time used during practice sessions. Instruction, conditioning, and warm-up were often accomplished outside of practice. In addition to the regular practice conducted on the soccer field, the team had an instructional session in the classroom that included video analysis of games and practices as well as instruction related to individual and team strategy. Instructional 
sessions were conducted two times a week before the afternoon practice session. In addition, the athletes were involved in physical conditioning including weight training and flexibility training.

Table 1. Total coaching behaviors, time spent for each practice session and practice segment.

\begin{tabular}{|c|c|c|c|c|c|c|c|c|}
\hline Date & $\begin{array}{l}\text { Practice } \\
\text { Segment }\end{array}$ & $\begin{array}{l}\text { Practice } \\
\text { Session }\end{array}$ & WU & $\mathrm{D}$ & $S$ & $\bar{C}$ & I & $\begin{array}{c}\text { Total } \\
\text { Behaviors }\end{array}$ \\
\hline $8 / 18 / 97$ & Early & $119: 21$ & & $6: 18$ & $77: 32$ & $14: 21$ & 7:03 & 26 \\
\hline $8 / 25 / 97$ & Early & $54: 22$ & $11: 20$ & & $41: 01$ & & 2:01 & 17 \\
\hline $8 / 28 / 97$ & Early & $97: 28$ & $6: 30$ & 33:00 & $44: 35$ & $7: 48$ & 1:00 & 31 \\
\hline Total & Early & $271: 11$ & $17: 50$ & $39: 18$ & $163: 08$ & 22:09 & 10:04 & 74 \\
\hline 9/4/97 & Mid & $84: 45$ & & $19: 10$ & $57: 45$ & & $4: 30$ & 52 \\
\hline 9/9/97 & Mid & 81:08 & & $24: 25$ & $45: 15$ & $6: 43$ & $1: 20$ & 62 \\
\hline $9 / 18 / 97$ & Mid & 69:50 & & $9: 50$ & $37: 20$ & $10: 50$ & $3: 10$ & 32 \\
\hline Total & Mid & $235: 43$ & 0:00 & $53: 25$ & $140: 20$ & $17: 33$ & 9:00 & 146 \\
\hline $10 / 2 / 97$ & Late & 74:00 & $8: 10$ & $20: 47$ & 29:50 & $8: 40$ & $3: 10$ & 46 \\
\hline 10/9/97 & Late & 72:05 & & $24: 30$ & $43: 30$ & $3: 30$ & & 53 \\
\hline $10 / 16 / 97$ & Late & $65: 00$ & $8: 05$ & & $33: 15$ & $6: 45$ & $14: 20$ & 37 \\
\hline $10 / 23 / 97$ & Late & $77: 10$ & $2: 40$ & $0: 50$ & $62: 40$ & & $4: 50$ & 39 \\
\hline Total & Late & $288: 15$ & $18: 55$ & $46: 07$ & $169: 15$ & $18: 55$ & $22: 20$ & 175 \\
\hline Total & Season & 795:09 & $36: 45$ & $138: 50$ & $472: 43$ & $58: 37$ & $41: 24$ & 395 \\
\hline & $\underline{\mathrm{M}}$ & 79:30 & $7: 21$ & $17: 21$ & $47: 16$ & $8: 22$ & $4: 36$ & 39.5 \\
\hline & $\underline{\mathrm{SD}}$ & 18:09 & 3:09 & $10: 46$ & $14: 37$ & $3: 26$ & 4:06 & 13.79 \\
\hline
\end{tabular}

Note: Time is in minutes and seconds. Warm-up (WU), Drills (D), Scrimmage (S), Conditioning (C), Instruction (I). 
Physical conditioning took place the other two days a week prior to the beginning of the afternoon practice. The head coach conducted all physical conditioning and instruction outside of the practice sessions. This physical conditioning outside of the regular scheduled practice may explain why the athletes did not spend every practice doing a warm up, since athletes often completed flexibility and conditioning just prior to the afternoon practice session. The additional time spent with the coach outside of practice may explain the very little time spent in conditioning and instruction during the regular practice session since the athletes were required to participate in these classes. The percentage of time spent in drills, however was less than would be anticipated. It would seem that the practice session would consist of more individualized time spent on drills that would improve an individual's soccer skills. The high percentage of time spent in the scrimmage segment may be due to the coach's priority for time use, particularly since instruction, conditioning, and warm up were focused on outside of practice time.

Practice segments were also examined to see if there were any differences in how the coach spent time among practices held during early, mid and late season. For example, Lacy and Darst (1985) found that more time was spent on drills to improve individual skills early in the season compared to late in the season. This is not consistent with the results of the present study. This study showed that all phases of the season, as well as segments of practice, were very similar as shown in Table 1.

With regard to coaching behaviors, previous research has shown coaching behaviors in a particular segment of practice varied depending on whether they were 
observed during the early season or late season (Lacy \& Darst, 1985; Langsdorf, 1979; Segrave \& Ciancio, 1990). As shown in Table 1, the present study found that more coaching behaviors were exhibited during the mid and late seasons compared to the early season. Lacy and Darst (1985) found that coaches' behaviors were higher in the preseason and were the same in the early season and late season.

Interobserver Reliability

Two graduate students were trained to make interobserver agreement (IOA) checks on both the CBAS and MSE data. Six randomly selected 10 minute segments (two from each phase of the season) were used for the IOA checks. There was a $88.50 \%$ agreement in the early season between the interobserver raters and the researcher, a $85.30 \%$ agreement in the mid season, and a $90.85 \%$ agreement in the late season for CBAS data. The overall interobserver agreement for the CBAS data was $88.22 \%$. There was a $97.35 \%$ agreement between the interobserver raters and the researcher for the MSE data. These values exceeded the accepted standard (85\%) for accuracy in behavioral research (Siedentop, 1991).

\section{Coaching Behaviors}

There were a total of 1570 coaching behaviors recorded in all observed practice sessions using the CBAS instrument (see Table 2). Of those behaviors, $1231(78.41 \%)$ were recorded as general behaviors, that is, behaviors without reference to the recipient and $339(21.59 \%)$ were recorded as specific behaviors, behaviors with reference to the recipient. Of all the CBAS behaviors including both general and specific, the most 
common behavior recorded was Reinforcement (22.42\%) of which $15.67 \%$ related to task oriented reinforcement (RT) and $6.75 \%$ related to ego oriented reinforcement (RE). The second most common recorded coaching behavior was organization (22.36\%). Mistake

Table 2. Percentages of General and Specific Coaching Behaviors

\begin{tabular}{|c|c|c|c|c|c|c|c|c|c|}
\hline \multirow{2}{*}{$\begin{array}{l}\text { Behavioral } \\
\text { Category }\end{array}$} & \multicolumn{3}{|c|}{ General (1231) } & \multicolumn{3}{|c|}{ Specific (339) } & \multicolumn{3}{|c|}{ Total $(1570)$} \\
\hline & Task & Ego & Total & Task & Ego & Total & Task & Ego & Total \\
\hline $\mathrm{R}$ & 10.89 & 5.28 & 16.17 & 33.04 & 12.09 & 45.13 & 15.67 & 6.75 & 22.42 \\
\hline EM & & & 4.79 & & & 4.13 & & & 4.65 \\
\hline TIM & & & 11.05 & & & 18.88 & & & 12.74 \\
\hline $\mathrm{P}$ & 1.71 & 1.46 & 3.17 & 1.47 & 0.88 & 2.36 & 1.66 & 1.34 & 2.99 \\
\hline $\mathrm{TIM}+\mathrm{P}$ & & & 1.46 & & & 0.88 & & & 1.34 \\
\hline $\mathrm{KC}$ & & & 0.73 & & & 0.59 & & & 0.70 \\
\hline TIG & & & 14.78 & & & 4.13 & & & 12.48 \\
\hline EG & & & 9.34 & & & 3.54 & & & 8.10 \\
\hline $\mathrm{O}$ & & & 24.29 & & & 15.34 & & & 22.36 \\
\hline GC & & & 14.22 & & & 5.01 & & & 12.2 \\
\hline
\end{tabular}

Contingent Technical Instruction (TIM) made up $12.74 \%$ of the coaching behaviors and General Technical Instruction (TIG) accounted for $12.48 \%$ of the coaching behaviors. In descending order, the remaining categories most often recorded were General Communication (GC) 12.23\%, General Encouragement (EG) 8.1\%, Mistake-Contingent Encouragement (EM) $4.65 \%$, and Punishment (P) 2.99\%. $1.66 \%$ of the punishment behaviors were task oriented punishment (PT) and $1.34 \%$ were ego oriented punishment (PE). Punitive Technical Instruction (TIM+P) accounted for $1.34 \%$ of the coaching behaviors, and Keeping Control (KC) accounted for $0.7 \%$.

Of the 339 specific behaviors coded with reference to the recipient, $45.13 \%$ were related to Reinforcement (R), of which $33.04 \%$ related to task oriented reinforcement 
(RT) and $12.09 \%$ related to ego oriented reinforcement (RE). The next most common behavior exhibited by the coach that made reference to the recipient was MistakeContingent Technical Instruction (TIM) which was $18.88 \%$ of the total specific behaviors. The third most common coaching behavior was Organization $(O)$, which accounted for $15.34 \%$ of all the specific behaviors coded. In descending order, the remaining coaching behavior categories were General Communication (GC) $5.01 \%$, both General Technical Instruction (TIG) and Mistake-Contingent Encouragement (EM) 4.13\%, General Encouragement (EG) $3.54 \%$, Punishment 2.36\%, of which $1.47 \%$ of the punishment interactions were task oriented punishment (PT), $0.88 \%$ were ego oriented punishment (PE), and .88\% were Punitive Technical Instruction. The lowest recorded coaching behavior was Keeping Control $(\mathrm{KC})$ which accounted for $0.59 \%$ of the specific coaching behaviors recorded.

This study supports the results of a previous study using the CBAS instrument (Krane, Eklund, \& McDermott, 1991). Krane et al. (1991) found that reinforcement was the most common behavior exhibited by the coach. In addition, previous research (Krane et al., 1991; Lacy \& Martin, 1994; Smith et al., 1979; Smoll et al., 1978) has shown that coaching behaviors exhibiting punitive components were rarely exhibited. The results of the present study are consistent with the results of the study conducted by Krane et al. (1991), in which the four most common coaching behaviors observed were Reinforcement, Mistake-Contingent Technical Instruction, Organization, and General Encouragement. Interestingly enough, Krane et al. (1991) also studied a collegiate soccer coach. The coach in the Krane et al. study, however, was a female coach of a women's 
collegiate soccer team with only a few years of experience at the collegiate level. Gender of the coaches in the two studies did not seem to have an effect on the observed coaching behaviors. Similar results with regard to gender have been found by other researchers (Lacy \& Goldston, 1990).

In comparison to the collegiate coach who was observed in the present study, earlier studies using the CBAS instrument were conducted with youth sport participants (Smith ci al., 1979; Smith et al., 1983; Smoll et al., 1978). The results of this study are consistent with youth sport studies. Youth sport studies found that nearly $75 \%$ of all coaching behaviors fell into three categories: Reinforcement, General Encouragement, and General Technical Instruction. In all studies regardless of age group (collegiate or youth) the four most common behaviors exhibited by the coaches were Reinforcement, General Technical Instruction, General Encouragement, and Organization. Punishment was rarely used by the coach in the present study. This finding is also consistent with the findings of previous studies (Smith et al., 1979; Smith et al., 1983; Smoll et al., 1978). In fact, Smoll et al. (1978) found Punishment to be the least observed behavior. One difference in the present study compared to previously mentioned studies was that Mistake-Contingent Technical Instruction was found to be used by the coach much more often than the studies conducted on youth sports. This difference might be due to the difference in the level of the athletes (youth vs. collegiate) or the level of skill (high skilled vs. low skilled) that the athletes in the present study have achieved.

An analysis and discussion of the data for each research question follows. There were five major research questions in the present study. 
1. What were the effects of the coach's verbal interactions on athlete effort (MSE)? To determine the effect of the interaction on effort CBAS behaviors were coded first. After the coach made reference to an athlete by name, MSE data were collected for the target athlete. Since an athlete may have responded to the coach's interaction for less than a minute all MSE data were reported in seconds. Because CBAS coaching behaviors can be categorized as positive or negative, Reinforcement, Mistake-Contingent Encouragement, Mistake-Contingent Technical Instruction, General Technical Instruction, and General Encouragement were grouped as positive interactions or those most likely to motivate the athlete (MSE). The other categories Punishment, Punitive Technical Instruction, and Keeping Control were grouped as negative interactions or not motivating athletes. For the purposes of answering research question number one, the categories of Organization and General Communication were not included because these behaviors have not been found to be of either motivational type (Smoll et al., 1978).

As shown in Table 3, 95.1\% of the coach's interactions were positive and $4.9 \%$ were negative. A totai of 11,485 seconds of athlete behavior was videotaped of which 10,949 seconds or $95.33 \%$ was coded as MSE. The coach's high level of positive interactions and very infrequent use of negative interactions is consistent with results found in another study that examined a female collegiate soccer coach (Krane et al., 1991). These results must be interpreted cautiously in that the findings are based on only $22 \%$ of all coaching behaviors. Seventy-eight percent of the coaching behaviors recorded in the present study were general (without reference to the recipient) and without reference to an athlete and because of this MSE can not be determined. 


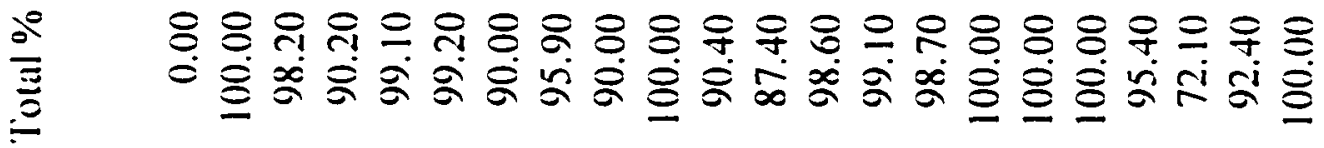

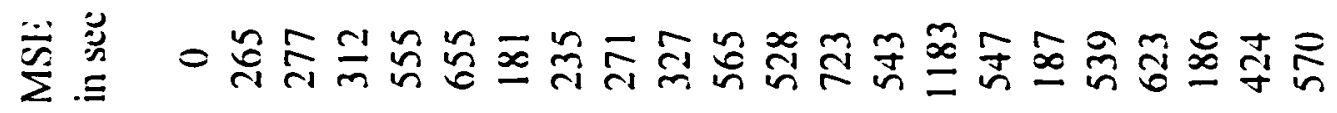

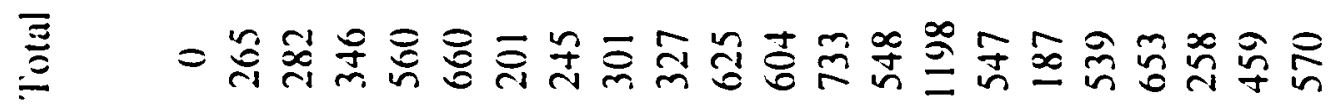

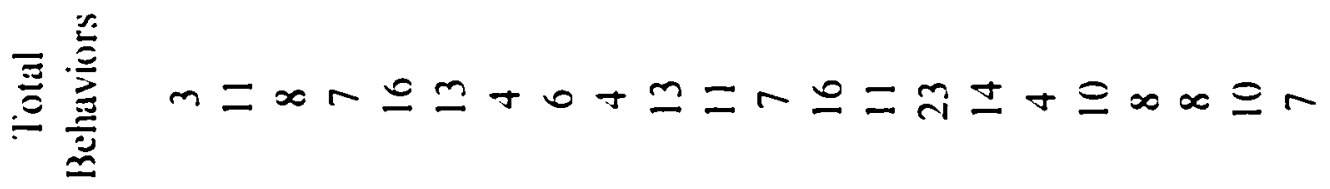

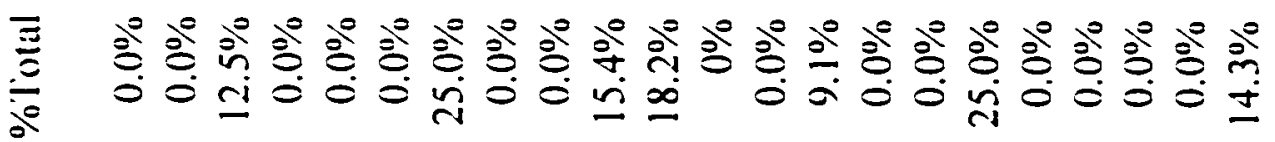

引ㅇㅎํ

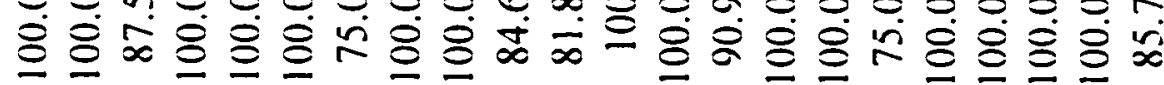

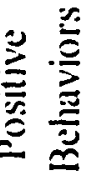

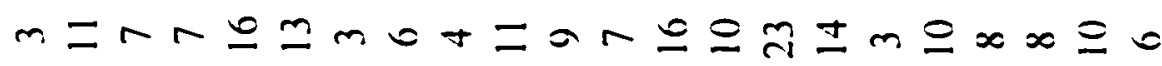

密

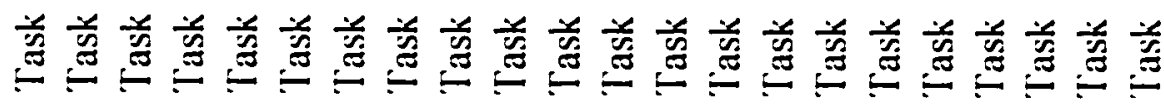

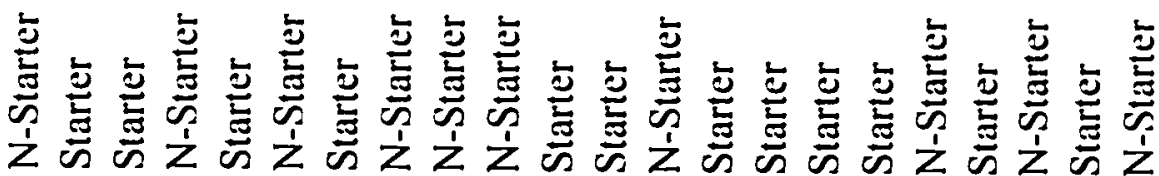

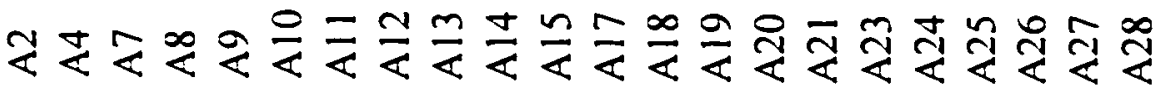




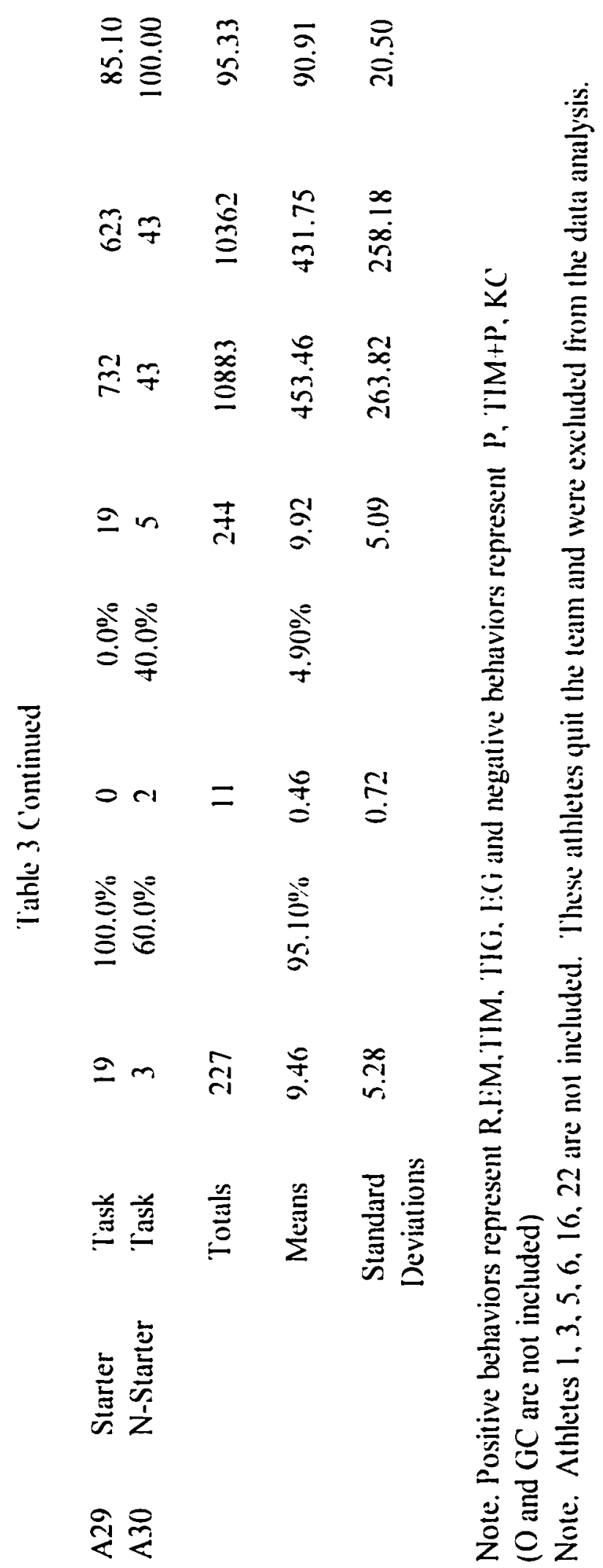


Unfortunately, $78 \%$ of all the potential MSE data is lost because the coach made no reference to an athlete.

Further analysis of the data showed that athletes MSE was similar for athletes of differing status which supports previous research (Lacy \& Martin. 1994). In addition, athletes in the present study, were for the most part, always appropriately engaged in MSE. This finding is consistent with past studies that have also found athlete appropriate MSE to be very high and inappropriate MSE to be very low at the collegiate and international level (Mancini \& Wuest, 1987; McKenzie, 1986; Wuest, Mancini, van der Mars, Terrillion, 1986). However, this study also investigated whether coach's interactions could have differentially affected effort (MSE) of athletes of differing goal orientation and status.

Given that only one athlete was ego oriented, discussing the differential effects of the coach's interactions on effort for this athlete is difficult. However, data from the starter task athletes showed that $61.67 \%$ of all the coach's positive interactions were given to the starters. Only $38.33 \%$ of the coach's interactions were given to nonstarter athletes (see Table 4). Howerer, when calculating MSE, it was found that the task oriented starters were appropriately engaged (MSE) $94.75 \%$ of the time, whereas the nonstarters were also appropriately engaged (MSE) $95.99 \%$ of the time. This finding indicates that despite the focus on positive coach interactions and its relationship to MSE, nonstarter task athletes were able to achieve high levels of MSE with less frequent positive coach interactions. This implies that another motivating force assists the nonstarter task athletes to stay appropriately engaged (MSE). Duda (1993) predicted 
in her achievement motivation theory that task oriented athletes tend to be mastery oriented, and as a result will exert more effort, thus be on task and motor engaged appropriately in the task. Studies examining the behavioral correlates of dispositional goal perspectives have found the emphasis placed on task involved goals to positively relate to effort exerted and sustained involvement in athletic settings. Regardless of starter status it appears in this study that goal orientation is a strong influence in achieving high MSE in college athletes which is consistent with Duda's achievement motivation theory.

Table 4. CBAS motivational behaviors and MSE to all types of athletes (starter task, starter ego, nonstarter task, nonstarter ego)

\begin{tabular}{|c|c|c|c|c|}
\hline \multirow{4}{*}{ Starter } & Task & Oriented & & Ego Oriented \\
\hline & CBAS & Total & $\%$ & \\
\hline & Behaviors & Behaviors & & \\
\hline & 140 & 227 & 61.67 & \\
\hline \multirow{7}{*}{ Nonstarter } & Total Sec. & Total MSE & Total \% & \\
\hline & 6861 & 6501 & 94.75 & \\
\hline & CBAS & Total & $\%$ & \\
\hline & Benaviors & Behaviors & & \\
\hline & & 2.2 & נJ.J & \\
\hline & Total Sec. & Total MSE & Total \% & \\
\hline & 4022 & 3861 & 95.99 & \\
\hline
\end{tabular}

2. What goal orientation(s) did the coach's verbal interactions encourage? Two categories of the CBAS instrument were used to examine whether or not a coach's interaction with the athlete was task oriented or ego oriented; Reinforcement and Punishment. Of the 1570 total coaching behaviors (see Table 2), 399 were related to task 
and ego orientation, of which 238 were recorded as general coaching behaviors, without reference to the recipient and 161 were recorded as specific, with reference to the recipient (see Table 5). Of the 238 general behaviors, $56.30 \%$ were coded as reinforcement task (RT), 8.82\% as punishment task (PT), $27.31 \%$ as reinforcement ego (RE), and $7.56 \%$ as punishment ego (PE). As shown in Table $5,65.13 \%$ of the total coaching behaviors were task oriented and $34.87 \%$ of the total coaching behaviors were ego oriented. Based on the predominate task orientation it can be concluded that the coach encouraged a task oriented environment $65.13 \%$ of the time and encouraged an ego environment $34.87 \%$ of the time.

Table 5. Total Task and Ego Coaching Behaviors

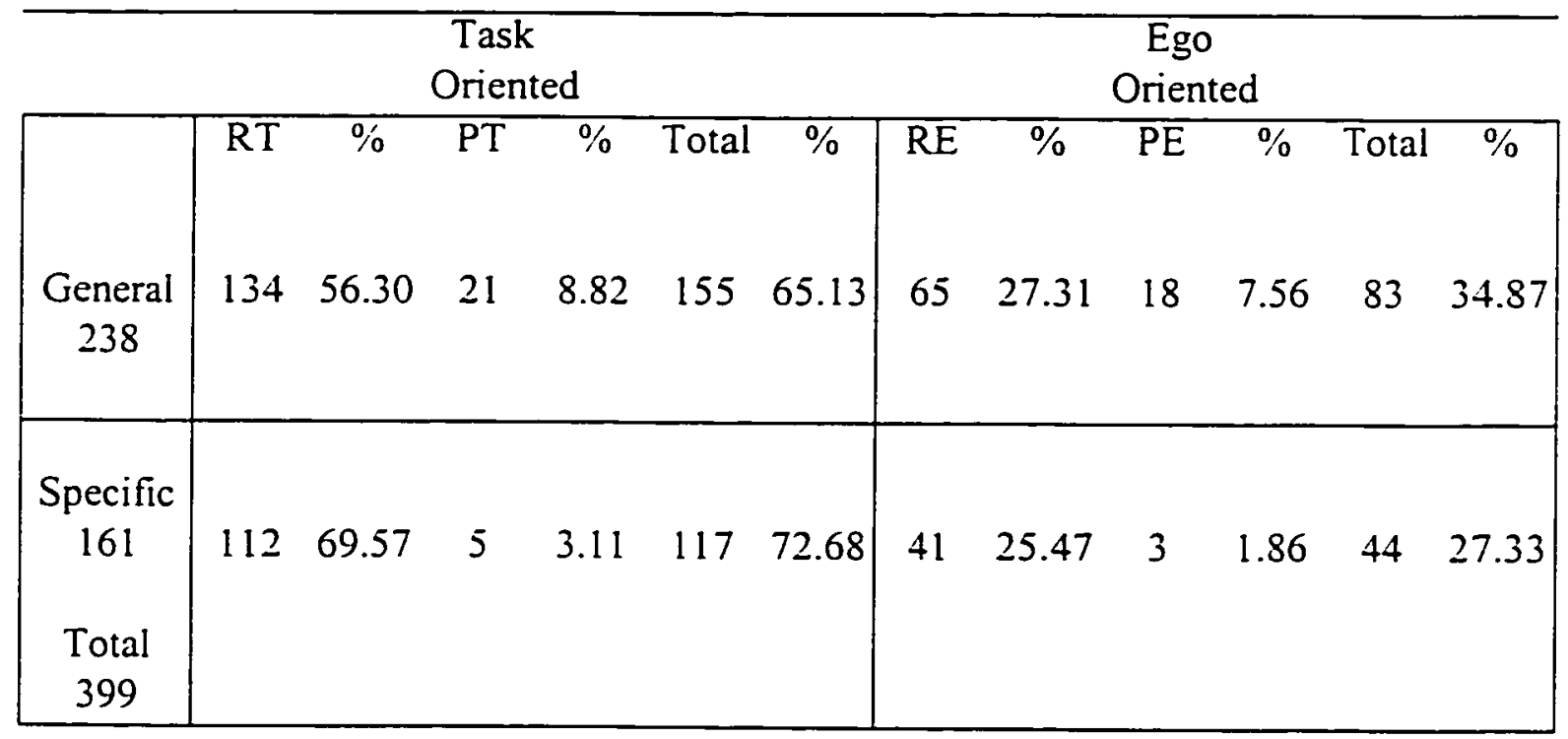

Out of the total of 161 specific behaviors that made reference to the recipient, $69.57 \%$ were reinforcement task (RT), $3.11 \%$ were punishment task (PT), $25.47 \%$ were reinforcement ego (RE), and $1.86 \%$ were punishment ego (PE). Given this, $72.68 \%$ were 
task oriented and $27.33 \%$ were ego oriented. The coach encouraged a task environment $72.68 \%$ and encouraged an ego environment $27.33 \%$ of the time.

Studies have shown that task oriented behaviors relate to increased participation, effort, and persistence in sport. From Nicholls' (1989) theoretical perspective the assumptions concerning the psychological and behavioral consequences of task and ego orientation in achievement contexts suggest that an emphasis on task oriented goals will tend to lead toward the exerting of maximal effort, good performance and continued participation. In competitive sport, the coach constitutes an important aspect of the social situation. Whether a coach creates and focuses on winning or skill improvement may influence the degree to which players adopt ego or task oriented goals. Duda (1992) suggested that if task involvement is so desirable from a motivational standpoint, the question remains how teachers and coaches can create and maintain a task oriented sport situation for their athletes and/or students? The effective coaching behavior guidelines developed by Smith et al. (1978) attempt to enhance players' motivation and self-esteem by encouraging coaches to de-emphasize the outcomes of players' actions and stress the exerting of effort and mastery of specific abilities .

3. Did the coach provide equitable motivation to all athletes based on whether the athlete was task or ego oriented or a starter or nonstarter? As shown in Table 4, 61.67\% of the coach's motivational interactions were made to starter task athletes, and $38.33 \%$ were made to nonstarter task athletes. These results show that the coach provided increased amounts of motivational interactions to the starter task athletes when compared to the nonstarter task athletes. This data is consistent with previous research which has 
demonstrated that coaches do not exhibit the same type of behaviors or provide the same type of feedback to all athletes on the team (Horn, 1985; Krane et al., 1991; Mancini \& Wuest, 1987; Markland \& Martinek, 1988; Rejeski et al., 1979). Mancini and Wuest (1987) found that coaches reinforced and accepted their high skilled athletes' efforts more than those efforts by the lesser skilled athletes. The predominant interaction patterns of the coaches showed that coaches interacted more and exhibited more varied behaviors toward the high skill athletes. Previous research has shown that lower skilled athletes not only received less feedback, but also the coaches tended to observe these athletes performance without comment for extended periods of time. Krane et al. (1991) found as other studies have (Mancini \& Wuest, 1987; Martinek, Crowe, \& Rejeski, 1982) that the majority of the Mistake-Contingent Technical Instruction was directed at the high skill athletes. Although level of skill was not a factor in this study, starter status appeared to influence the coach's distribution on motivational interactions.

4. How accurately did the coach's perception of his actions relate to his actual verbal interactions with athletes of differing status and goal orientation? The coach's perceptions of his own behavior questionnaire required the coach to respond to varicus questions related to his verbal behavior using the following 7-point likert scale: 7-almost always, 6-very often, 5-quite often, 4-seldom, 2-hardly ever, and 1-never (see Appendix D). Since there was only one ego oriented athlete, that data was not included in the analysis. Only data from task oriented athletes will be discussed in reference to this research question. As shown in Table 6, there are mixed results as to the coach's accurate perception of his actual behaviors. The coach was most accurate in his 
Table 6. Actual Coach Behaviors for Athletes Status and Goal Orientation and Coach's Perception of Own Behaviors

\begin{tabular}{lrrrrrrrl}
\hline $\begin{array}{l}\text { Behavioral } \\
\text { Category }\end{array}$ & ST & $\%$ & NST & $\%$ & Total & $\%$ & $\begin{array}{c}\text { Coach } \\
\text { Perception }\end{array}$ \\
\hline R & 69 & 40.59 & 58 & 44.62 & 127 & 22.42 & 7 & 1 \\
EM & 8 & 4.71 & 5 & 3.85 & 13 & 4.65 & 7 & 1 \\
TIM & 34 & 20.00 & 30 & 23.08 & 64 & 12.74 & 4 & 7.5 \\
P & 4 & 2.35 & 4 & 3.08 & 8 & 3.00 & 1 & 10 \\
TIM+P & 1 & 0.59 & 2 & 1.54 & 3 & 1.34 & 2 & 9 \\
KC & 0 & 0.00 & 1 & 0.77 & 1 & 0.70 & 4 & 7.5 \\
TIG & 9 & 5.29 & 4 & 3.08 & 13 & 12.48 & 7 & 1 \\
EG & 5 & 2.94 & 6 & 4.62 & 11 & 8.10 & 6 & 6 \\
O & 30 & 17.65 & 16 & 12.31 & 46 & 22.36 & 7 & 1 \\
GC & 10 & 5.88 & 4 & 3.08 & 14 & 12.23 & 7 & 1 \\
& & & & & & & & \\
Total & 170 & 100 & 130 & 100 & 300 & & &
\end{tabular}

perception with regard to Reinforcement. The coach rated himself giving Reinforcement (R) "almost always" (7). In addition, Reinforcement was the most often coaching behavior provided to the starter task athletes $(40.59 \%)$, and to the nonstarter task athletes (44.62\%). Krane et al. (1991) found that the coach in that study consistently underestimated her use of positive reinforcement. While she estimated that $20 \%$ to $25 \%$ of her behaviors in each practice session fell into this category, her actual reinforcing behaviors ranged from $34 \%$ to $52 \%$. The coach in the present study perceived himself as "never" (1) giving Punishment but was observed throughout the season giving Punishment to the starter task athletes $2.35 \%$ of the time, and to the nonstarter task athletes $3.08 \%$ of the time. These percentages might more closely represent "hardly ever" (2), not "never" (1) as perceived by the coach. The coach perceived himself as 
"sometimes" (4) giving Mistake-Contingent Technical Instruction and was observed throughout the season giving Mistake-Contingent Technical Instruction $20.00 \%$ of the time to starter task athletes, and $23.08 \%$ of the time to nonstarter task athletes. Krane et al. (1991) found that the coach consistently overestimated her Mistake-Contingent Technical Instruction. The coach in this study was accurate in his perceived behaviors when compared to his observed behaviors with regard to Reinforcement, Punishment, Punitive Technical Instruction, Organization, and Mistake-Contingent Technical Instruction.

There were other coach perceptions that were not found to relate with the coach's actual interactions. The inaccuracy of recalling behaviors in some of the categories is consistent with previous studies (Krane et al., 1991; Smith et al., 1979; Wandzilak and Ansorge, 1988). The coach perceived himself as "always" (7) giving Mistake-Contingent Encouragement, but was only observed giving $4.71 \%$ Mistake Contingent Encouragement to the starter task athletes and $3.85 \%$ to the nonstarter task athletes. The coach also perceived himself as "always" (7) giving General Technical Instruction but was observed giving only $5.29 \%$ of his interactions as General Technical Instruction to starter task athletes and $3.08 \%$ to the nonstarter task athletes. The coach perceived himself as "very often" (6) giving General Encouragement but he was only observed giving $2.94 \%$ of his interactions as General Encouragement to starter task athletes and $4.62 \%$ to non starter task athletes. The coach was inaccurate in his perceived behaviors when compared to his observed behaviors in the following categories: MistakeContingent Encouragement, General Technical Instruction, and General Encouragement. 
5. How accurately did the athletes' perception of their coach's interactions relate to his actual verbal interactions with athletes of differing status and goal orientation? The athletes' perceptions of the coach's behavior questionnaire required the athletes to respond to various questions related to the coach's verbal behavior using the following 7-point Likert scale: 7-almost always, 6-very often, 5-quite often, 4-seldom, 2-hardly ever, and 1-never (see Appendix E). As shown in Table 7, there are mixed results as to the athletes' perceptions of the coach's interactions. Although the actual behavior of the coach was very positive and reinforcement was the highest percentage of all the interactions, the athletes did not perceive the coach the same way. Overall, the athletes perceived the coach as providing reinforcement "sometimes" (4.8) to "quite often" (5). Starters perceived the coach as positive, but perceived him as providing Reinforcement only "quite often" (5.15) even though $40.59 \%$ of his interactions to the starter athletes were categorized as Reinforcement. The nonstarters perceived the coach as positive, but rated him as providing Reinforcement "sometimes" (4.36). The nonstarters received Reinforcement interactions $44.62 \%$ of the time. It is interesting to note that although the nonstarter task athletes perceived the coach as providing less reinforcement (4.36) when compared to the starter task athletes $(5.15)$, the nonstarter task athletes received more reinforcement $(44.62 \%)$ than the starter task athletes $(40.59 \%)$.

Overall, the athletes perceived the coach as providing Punishment "hardly ever" to "seldom" (2.92). Starters perceived the coach as providing Punishment "hardly ever" (2.46), and $2.35 \%$ of his interactions were categorized as Punishment. The nonstarters perceived the coach providing Punishment "seldom" to "sometimes" (3.64). 


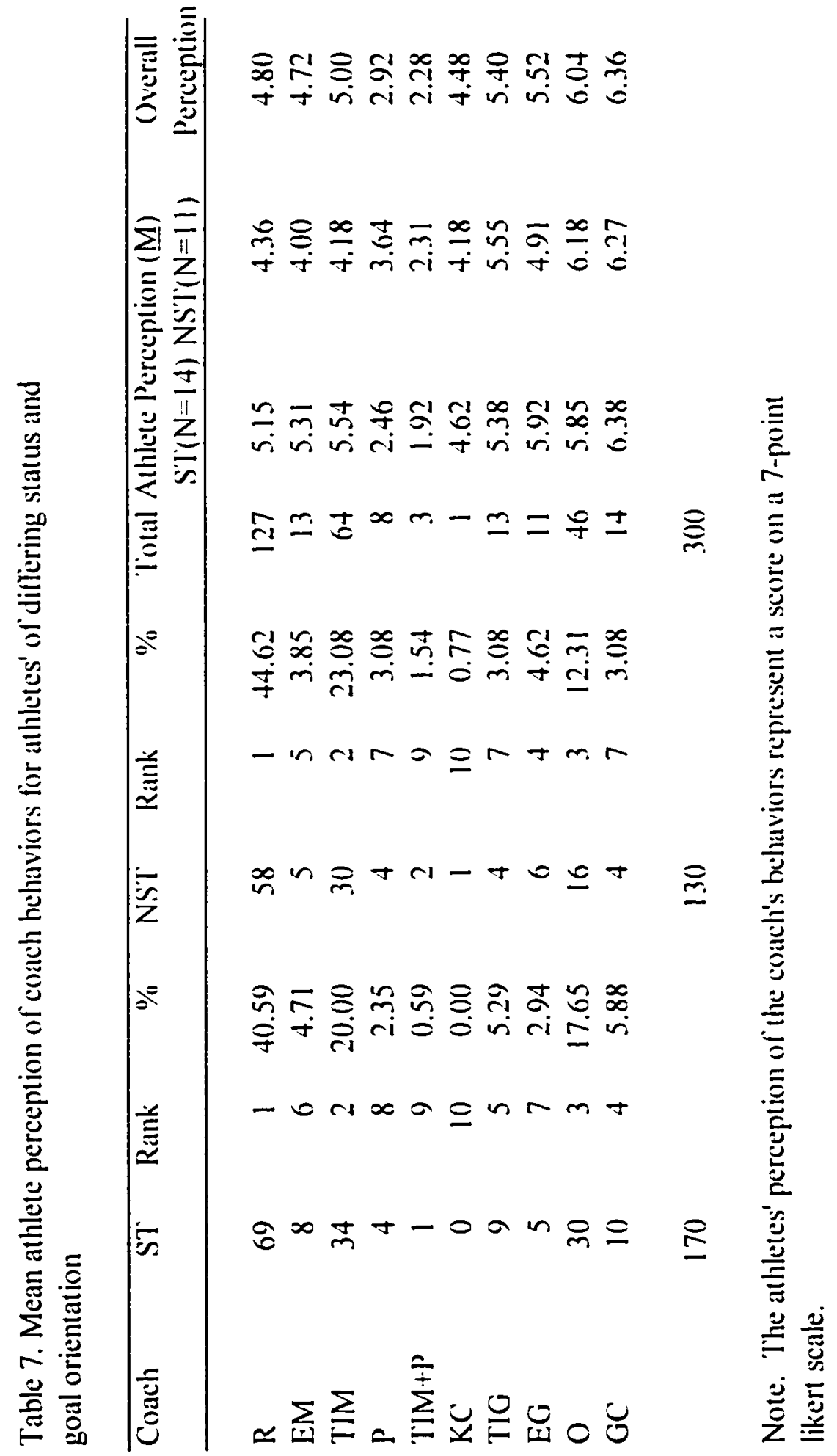


The nonstarters received Punishment interactions $3.08 \%$ of the time. The nonstarter athletes' perceptions of receiving punishment is dissimilar. Of all the coach's interactions, only $2.35 \%$ to $3.08 \%$ were punishment. It is interesting to note the inflated perception nonstarter task athletes had for receiving punishment.

Overall, the athletes perceived the coach as providing Mistake-Contingent Technical Instruction "quite often" (5.00). Starters perceived the coach as providing Mistake-Contingent Technical Instruction "quite often" (5.54), but only $20.00 \%$ of the coach's interactions were categorized as Mistake-Contingent Technical Instruction. This percentage is better represented as "sometimes" (4), not "quite often" (5) as perceived by the athletes. The nonstarters perceived the coach providing Mistake-Contingent Technical Instruction "sometimes" (4.18). The nonstarters received Mistake-Contingent Technical Instruction interactions $\mathbf{2 3 . 0 8 \%}$ of the time. It is interesting to note that although the nonstarter task athletes perceived the coach as providing less MistakeContingent Technical Instruction (4.18) when compared to the starter task athletes (5.54), the nonstarter task athletes received more Mistake-Contingent Technical Instruction $(23.08 \%)$ than the starter task athletes $(20.00 \%)$.

Overall, the athletes perceived the coach as providing General Encouragement "quite often" (5.52). Starters perceived the coach as providing General Encouragement "quite often" to "very often" (5.92), but only $2.94 \%$ of his interactions were categorized as General Encouragement. The nonstarters perceived the coach providing General Encouragement "sometimes" to "quite often" (4.91). The nonstarters received General 
Encouragement interactions $4.62 \%$ of the time. It is interesting to note that although the nonstarter task athletes perceived the coach as providing less General Encouragement (4.91) when compared to the starter task athletes (5.92), the nonstarter task athletes received more General Encouragement (4.62\%) than the starter task athletes $(2.94 \%)$. Regardless of athlete status or goal orientation, the athletes' perception of the coach was similar to the observed behaviors for the following categories; Reinforcement, Punishment, Punitive Technical Instruction, and Organization. The athletes' perception of the coach was different than the observed behaviors for the following categories; Keeping Control, General Technical Instruction, General Encouragement, and General Communication. A general pattern was found regarding nonstarter athletes' perceptions of certain coach behaviors. Nonstarter athletes consistently misperceived the coach's behaviors. Even though the actual observed behaviors of the coach showed that the nonstarter athletes received more coaching behaviors than the starter task athletes, the nonstarter athletes perceived the coach as providing less Reinforcement, MistakeContingent Technical Instruction, and General Encouragement. Also, the nonstarter task athletes perceived the coach as providing more punishment.

There were three interesting findings in the present study. Nonstarter task oriented athletes received less positive interactions (61.6\% vs. $38.3 \%)$ from the coach and yet were found to be appropriately engaged (MSE for starter tasks, 94.75\%, MSE for nonstarter tasks $95.99 \%$ ) slightly more than the starter task athletes. This finding indicates that despite the coach's focus on positive interactions and its relationship to MSE, nonstarter task athletes were able to achieve high levels of MSE with fewer 
positive coach interactions. This study also found that only $22 \%$ of all coach interactions were coded with reference to the recipient and $78 \%$ of the coach's interactions were coded without reference to the recipient. The data without reference to the recipient can not be coded as MSE because of its lack of reference to an athlete by name. This potential data for MSE is undetermined and may have affected MSE results had the coach used the athletes' name. Finally, the nonstarter athletes had an dissimilar perception of the coach's behaviors. Specifically, the nonstarter athletes were not accurate in the perceptions of the coach as providing Reinforcement, Punishment, Mistake-Contingent Technical Instruction, and General Encouragement. These findings suggest future research is necessary. 


\section{Chapter 5}

\section{$\underline{\text { Summary }}$}

The purposes of the present study were to determine the effects of a coach's verbal interactions on athlete effort as measured by motor skill engagement, to determine which goal orientation(s) the coach encouraged, if the coach provided equitable motivation to all types of athletes (starter, nonstarter, task oriented, ego oriented), and to determine how accurate the coach's perception and the athlete's perception of the coach's verbal interactions related to the actual verbal interactions with the athletes of differing status and goal orientation.

Data were reported for one coach and 25 athletes who finished the season. Of the 25 athletes identified by the coach, 14 were starters and 11 were nonstarters. As determined by the TEOSQ (Duda \& Nicholls, 1991) $96 \%$ of the athletes were found to be task oriented. A total of 10 practice sessions (three early-season, three mid-season, four late-season) were observed. Examination of all phases of the season as well as all segments of practice were also observed. Contrary to previous studies where the coach's interactions were highest during early in the season, the present study found that more interactions were observed during the mid and late phases of the season.

Reinforcement was the most common coaching behavior as defined by the CBAS and punitive coaching behaviors were the least common exhibited by the coach. The four most commonly observed behaviors were reinforcement, mistake-contingent technical instruction, organization, and encouragement. Although the present study observed a collegiate coach, earlier studies conducted with youth sport participants (Smith et al., 
1979; Smith et al., 1983; Smoll et al., 1978) have found similar results. These studies found that nearly $75 \%$ of all coaching behaviors fell into three categories: reinforcement, general encouragement, and general technical instruction.

Athlete MSE was found to be similar between athletes' status and goal orientation, which is consistent with previous research (Lacy \& Martin, 1994). Athletes were, for the most part, always appropriately engaged. Data showed that $61.6 \%$ of all the coach's positive interactions were given to the starters. Only $38.3 \%$ of the coach's interactions were given to nonstarters. However, when calculating MSE, this study found that the task oriented starters were appropriately engaged (MSE) $94.75 \%$ of the time, where as the nonstarters were also appropriately engaged (MSE) $95.99 \%$ of the time. This finding indicates that despite the coach's focus on positive interactions, nonstarter task athletes were able to achieve high levels of MSE with less positive coach interactions.

One aspect of this study was to determine which goal orientation(s) the coach encouraged. Surprisingly, $96 \%$ of the athletes were task oriented. The analysis of general behavior data (without reference to the recipient) showed that, the coach encouraged a task environment $68.17 \%$ of the time and encouraged an ego environment $31.83 \%$ of the time. The analysis of specific behavior data (with reference to the recipient) showed that, the coach encouraged a task environment $72.67 \%$ and encouraged an ego environment $27.33 \%$ of the time.

This study also determined how accurate a coach's perceptions of his own behaviors were compared with his actual behaviors. The coach was accurate in his 
perception when compared to his observed behaviors with regard to Reinforcement. Punishment, Punitive Technical Instruction, Organization, and Mistake-Contingent Technical Instruction. The coach was inaccurate in his perception behaviors when compared to his observed behaviors in the following categories: Mistake-Contingent Encouragement, General Technical Instruction, and General Encouragement.

Regardless of athlete status or goal orientation, the athletes' perception of the coach was similar to the observed behaviors for the following categories; Reinforcement, Punishment, Punitive Technical Instruction, and Organization. The athletes' perceptions of the coach were different than the observed behaviors for the following categories; Keeping Control, General Technical Instruction, General Encouragement, and General Communication. The nonstarter athletes had a dissimilar perception of the coach's behaviors. Several misperceptions, particularly; Reinforcement, Punishment, MistakeContingent Technical Instruction, and General Encouragement from the nonstarter athletes need to be reexamined.

\section{Conclusions}

The following conclusions can be made based on the results of the present study:

1. The collegiate coach studied was found to be positive in his interactions with the athletes regardless of status or goal orientation.

2. The collegiate coach studied was found rarely exhibiting punitive behaviors with the athletes regardless of status or goal orientation.

3. The coach was found to encourage a task oriented environment, which has been shown by Duda (1993) to be the type of orientation needed for improved performance 
and continuation in sport.

4. The coach was found to provide more positive interactions to starter task athletes than to nonstarter task athletes.

5. Even though the coach provided more positive interactions to starter task athletes, nonstarter task athletes were found to be appropriately engaged in MSE slightly more than starter task athletes.

6. There was a substantial amount of potential MSE data that could not be determined because the coach made no reference to the recipient. Seventy-eight percent of the data in the present study could not be coded with reference to the recipient. Only $21.59 \%$ of the data were coded for MSE data.

7. The nonstarter athletes' perceptions of the coach's behaviors were dissimilar on the following categories: Reinforcement, Punishment, Mistake-Contingent Technical Instruction, and General Encouragement.

8. The coach's behaviors in the present study were found to be similar to studies that have been conducted on youth sports, indicating that there may be similarities among the types of interactions between coaching behaviors found at the collegiate and youth levels.

9. The goal orientation of the athletes based on the TEOSQ (Duda \& Nicholls, 1991) was found to be primarily task oriented.

10. Athletes were found to be almost always appropriately engaged in MSE. 


\section{Practical Implications}

The following have practical implications for coaches based on the results of the present study:

1. Since most $(96 \%)$ collegiate athletes were found to be task oriented, coaches may want to create a task oriented environment during practice.

2. Regardless of athlete status and goal orientation, coaches should exhibit a high ratio of reinforcement and positive behaviors.

3. Regardless of athlete status and goal orientation, coaches should exhibit a low ratio of punishment and negative behaviors.

4. Athletes task orientation may be a more influential factor in athlete's effort, as measured by motor skill engagement, than the coach's verbal interactions.

5. Encouraging a task oriented environment is recommended to increase athletes' effort as measured by motor skill engagement.

6. Encouraging an ego oriented environment should be limited.

7. Coaches should exhibit more behaviors toward individual athletes and be more conscientious to make sure athletes know that the feedback was intended for them by using the athlete's name.

8. Coaches may want to have an open dialogue with athletes in regards to certain coaching behaviors they exhibit, particularly to nonstarter athletes. 


\section{$\underline{\text { Recommendations for Future Research }}$}

For future research, the following recommendations can be made based on the results of the present study:

1. The need to replicate this study increasing the number of coaches and teams.

2. To conduct studies that focus on different sports.

3. To conduct studies that focus on different competitive levels.

4. To conduct studies that include both male and female teams.

5. To conduct studies that include both male and female coaches.

6. Since most studies to date do not focus on the entire season, more studies need to be conducted throughout the entire season.

7. The need to conduct studies that investigate if increased levels of MSE lead to improved performance.

8. The need to conduct studies that investigate if increased levels of MSE lead to changes in goal orientation.

9. Future studies need to address how a coach can affect or change an athlete's goal orientation.

10. There is also a need to investigate the relationship between coaching behaviors and athletes' goal orientation.

11. If future studies find similar results to the present study with regard to the nonstarter athletes' perception of the coach's actual behavior with regard to punishment, reinforcement, mistake-contingent technical instruction, and general encouragement 
then follow up interviews need to take place to provide a more in depth understanding of the factors affecting the nonstarter athletes' perceptions of the environment. 


\section{$\underline{\text { References }}$}

Ames, C. (1992). Achievement goals, motivational climate, and motivational process. In G.C. Roberts (Ed.), Motivation in sport and exercise (pp. 161-176). Champaign, IL: Human Kinetics.

Barrow, J. (1977). The variables of leadership: A review and conceptual framework. Academy of Management Review, 2, 231-251.

Black, J.S., \& Weiss, M.R. (1991). The relationship among perceived coaching behaviors, perceptions of ability, and motivation in competitive age-group swimmers. Joumal of Sport \& Exercise Psvchology, 1992, 14, 309-325.

Burton, D. (1989). Winning isn't everything: Examining the impact of performance goals on collegiate swimmers' cognitions and performance. The Sport Psychologist. 3. 105-132.

Chaumeton, N.L., \& Duda, J.L. (1988). Is it how you play the game or whether you win or lose? The effect of competitive level and situation on coaching behaviors. Journal of Sport Behavior, 11, 157-174.

Chelladurai, P. (1990). Leadership in Sports: A review. International Journal of Sport Psychology. 21, 328-354.

Claxton, D.B. (1988). A systematic observation of more and less successful high school tennis coaches. Joumal of Teaching in Physical Education, 7 , 302-310.

Darst, P.W., Zakrajsek, D.B., \& Mancini, V.H. (1989). Analyzing physical education and sport instruction (2nd ed.). Champaign, IL: Human Kinetics.

Duda, J.L. (1988). The relationship between goal perspectives and persistence and intensity among recreational sport participants. Leisure Sciences, 10, 95-106.

Duda, J.L. (1989). Relationship between task and ego orientation and the perceived purpose of sport among high school athletes. Journal of Sport \& Exercise Psychology, $11,318-335$.

Duda, J.L. (1992). Motivation in sport settings: A goal perspective approach. In G.C. Roberts (Ed.), Motivation in sport and exercise (pp. 57-91). Champaign, IL: Human Kinetics.

Duda, J.L. (1993). Goals: A social-cognitive approach to the study of achievement motivation in sport. In S. Serpa, M. Murphey, \& L.K. Tennant (Eds.), Handbook on Research in Sport Psychology (pp. 421-436). New York, NY: Macmillan. 
Duda, J.L., \& Nicholls, J.G. (1991). The Task and Ego Orientation in Sport Questionnaire: Psychometric properties: Manuscript submitted for publication.

Duda, J.L., \& Nicholls, J.G. (1992). Dimensions of achievement motivation in schoolwork and sport. Journal of Educational Psychology, 84, 290-299.

Duda, J.L., \& White, S. (1992). Goal orientations and beliefs about the causes of sport success among elite skiers. Sport Psychologist, 6, 334-343.

Dweck, C.S. (1986). Motivational processes affecting learning. American Psvchologist, $41,1040-1048$.

Gill, D.L. (1986). Psychological dynamics of sport. Champaign, IL: Human Kinetics

Gould, D., \& Weinberg, R.S. (1995). Foundations of sport and exercise psychology. Champaign, IL: Human Kinetics.

Hom, H.L., Duda, J.L., \& Miller, A. (1993). Correlates of goal orientations among youth athletes. Pediatric Exercise Science, 5, 168-176.

Horn, T.S. (1985). Coach's feedback and changes in children's perceptions of their physical competence. Joumal of Educational Psychology, 77, 174-186.

Horn, T.S. (1992). Leadership effectiveness in the sport domain. In T.S. Hom (Ed.), Advances in sport psychology (pp. 181-199). Champaign, IL: Human Kinetics.

Krane, V., Eklund, R., \& McDermott, M. (1991). Collaborative action research and behavioral coaching intervention: A case study. Applied Research in Coaching and Athletics Annual, 119-147.

Lacy, A.C. (1989). Behavioral analysis of youth sport soccer coaches. Poster presented at the 1989 AAHPERD National Convention, Boston, MA.

Lacy, A.C. \& Darst, P.D. (1984). The evolution of a systematic observation instrument: The ASU Observation Instrument. Journal of Teaching in Physical Education, 3, 59-66.

Lacy, A.C, \& Darst, P.D. (1985). Systematic observation of behaviors of winning high school head football coaches. Journal of Teaching in Physical Education, 4, 256270. 
Lacy, A.C. \& Goldston, P.D. (1990). Behavior analysis of male and female coaches in high school girls' basketball. Journal of Sport Behavior, 13, 29-39.

Lacy, A.C., \& Martin, D.L. (1994). Analysis of starter/nonstarter motor-skill engagement and coaching behaviors in collegiate women's volleyball. Journal of Teaching in Physical Education, 13, 95-107.

Langsdorf, E.V. (1979). A systematic observation of football coaching behavior in a major university environment (Doctoral Dissertation, Arizona State University, 1979). Dissertation Abstracts International, 40, 4473A.

Luthans, F. (1979). Leadership: A proposal for a social learning theory base and observational and functional analysis techniques to measure leader behavior. In J.G. Hunt \& L.L. Larson (Eds.), Crosscurrents in leadership (pp. 201-208). Carbondale, IL: Southern Illinois University Press.

Marini, V.H. \& Wuest, D.A. (1987). Coaches' interactions and their high-and lowskilled athletes' ALT-PE: A systematic perspective. In G.T. Barrette, R.S. Feinfold, C.R. Rees, \& M. Pieron (Eds.), Myths, models, and methods in sport pedagogy (pp. 117 122). Champaign, IL: Human Kinetics.

Markland, R., \& Martinek, T. (1988). Descriptive analysis of coach augmented feedback given to high school varsity female volleyball players. Journal of Teaching in Physical Education. 7.289-301.

Martinek, T.J., Crowe, P.B., \& Rejeski, W.J. (1982). Pygmalion in the gym: Causes and effects of expectations in teaching and coaching. West Point, NY: Leisure Press.

Martens, R. (1978). Jov and sadness in children's sports. Champaign, IL: Human Kinetics, 1978, 9-10, 307-315.

Martin, G.L., \& Hrycaiko, D. (1983). Behavior modification and coaching: Principles, procedures and research. Springfield, IL: Charles C. Thomas.

Martin, G.L., \& Lumsden, J.A. (1987). Coaching: An effective behavioral approach. St. Louis, MO: Times Mirror/Mosby.

McKenzie, T.L. (1986). Analysis of the practice behavior of elite athletes. In M. Pieron \& G. Graham (Eds.), Sport pedagogy (pp.117-121). Champaign, IL: Human Kinetics.

Model, R. (1983). Coaching behavior of non-winning high school football coaches in Arizona (Doctoral Dissertation, Arizona State University, 1983). Dissertation Abstracts International, 44. 703A. 
Nicholls, J.G. (1989). The competitive ethos and democratic education. Cambridge, MA: Harvard University Press.

Piparo, A.J., Lewthwaite, R., \& Hasbrook, C.A. (1993). Social correlates of children's sport goal orientations: Coach behaviors and societal influences. Joumal of Research in Personality, 27, 103-117.

Rejeski, W., Darracott, C., \& Hutslar, S. (1979). Pygmalian in youth sport: A field study. Journal of Sport Psychology, 1, 311-319.

Rosenshine, B.V. (1979). Content, time, and direct instruction. In P.L. Peterson \& H.J. Walberg (Eds.), Research on teaching: Concepts, findings, and implications (pp. 2856). Berkeley, CA: McCutchan.

Rupert, T. \& Buschner, C. (1989). Teaching and coaching: A comparison of instructional behaviors. Journal of Teaching in Phvsical Education, 9, 49-57.

Rushall, B.S. (1977). Two observation schedules for sporting and physical education environments. Canadian Joumal of Applied Sport Sciences, 2, 15-21.

Rushall, B.S. (1983). Coaching styles: A preliminary investigation. In G.L. Martin, \& D. Hrycaiko, (Eds), Behavior modification and coaching: Principles, procedures, and research (pp. 299-319). Springfield, IL: Charles C. Thomas.

Rushall, B.S., \& Siedentop, D. (1972). The development and control of behavior in sport and physical education. Philadelphia, PA: Lea \& Febiger.

Segrave, J.O. \& Cianco, C.A. (1990). An observational study of a successful Pop Warner football coach. Journal of Teaching in Physical Education, 9, 294-306.

Siedentop , D. (1991). Developing teaching skills in physical education (3rd ed). Mountain View, CA: Mayfield Publishing Company.

Skinner, B.F. (1953). Science and human behavior. New York: Macmillan.

Smith, R.E., \& Smoll, F.L., \& Hunt, E. (1977). A system for the behavioral assessment of athletic coaches. Research Quarterly, 48, 403-407.

Smith, R.E., Smoll, F.L., Hunt, E., Curtis, B., \& Coppel, D.B. (1978). Psychology and the bad news bears. In G.C. Roberts \& K.M. Newell (Eds.), Psychology of motor behavior and sport (pp. 109-130). Champaign, IL: Human Kinetics. 
Smith, R.E., Smoll, F.L., \& Curtis, B. (1979). Coach effectiveness training: A cognitive-behavioral approach to enhancing relationship skills in youth sport coaches. In G.L. Martin, \& D. Hrycaiko, (Eds.), Behavior modification and coaching: Principles. procedures, and research (pp. 337-358). Springfield, IL: Charles C. Thomas.

Smith, R.E., Zane, N., Smoll, F.L., \& Coppel, D. (1983). Behavioral assessment in youth sports: Coaching behaviors and children's attitudes. Medicine and Science in Sports and Exercise, 15, 208-214.

Smoll, F.L., Smith, R.E., Curtis, B., \& Hunt, E. (1978). Toward a mediational model of coach-player relationships. Research Quarterly for Exercise and Sport, 49, 528-541.

Smoll, F.L., Smith, R.E. (1980). Psychologically oriented coach training programs: Design, implementation, and assessment. In C.H. Nadeau, W.R. Halliwell, K.M. Newell, \& G.C. Roberts (Eds.), Psychologv of motor behavior and sport. Champaign, IL: Human Kinetics.

Smoll, F.L., Smith, R.E. (1984). Leadership research in young athletes. In J. Silva \& R. Weinberg (Eds.), Psychological foundations of sport. Champaign, IL: Human Kinetics.

Smoll, F.L., \& Smith, R.E. (1989). Leadership behaviors in sport: A theoretical model and research paradigm. Journal of Applied Social Psychologv, 19, 1522-1551.

Straub, W.F. (1978). Sport psychology: An analysis of athlete behavior. Ithaca, NY: Mouvement Publications.

Tharp, R. \& Gallimore, R. (1976, January). What a coach can teach a teacher. Psvchologv Todav, 75-78.

van der Mars, H. (1989). Systematic Observation: An introduction. In P.W. Darst, D.B. Zakrajsek, \& V.H. Mancini (Eds.), Analyzing physical education and sport instruction (2nd ed.) (pp. 3-17). Champaign, IL: Human Kinetics.

van der Mars, H., Darst, P., \& Sariscsany, M.J. (1991). Practice behaviors of elite archers and their coaches. Journal of Sport Behavior, 14, 103-112.

Wandzilak, T. \& Ansorge, C.J. (1988). Comparison between selected practice and game behaviors of youth sport soccer coaches. Journal of Sport Behavior, 11, 78-88.

Weiss, M.R., \& Chaumeton, N. (1992). Motivational orientations in sport. In T.S. Horn (Ed.), Advances in sport psychology (pp. 61-99). Champaign, IL: Human Kinetics. 
Westre, K.R., \& Weiss, M.R. (1991). The relationship between perceived coaching behaviors and group cohesion in high school football teams. The Sport Psychologist. 5 . 41-54.

Williams, J.K. (1978). A behavior analysis of a successful high school basketball coach. Unpublished master's thesis, Arizona State University.

Wuest, D.B., Mancini, V.H., van der Mars, H., \& Terillion, K. (1986). The academic learning time-physical education of high-, average-, and low-skilled female intercollegiate volleyball players. In M. Pieron \& G. Graham (Eds.), Sport pedagogy (pp. 123-129). Champaign, IL: Human Kinetics. 
Appendixes 
Appendix A

Smoll and Smith's Model (1989) 


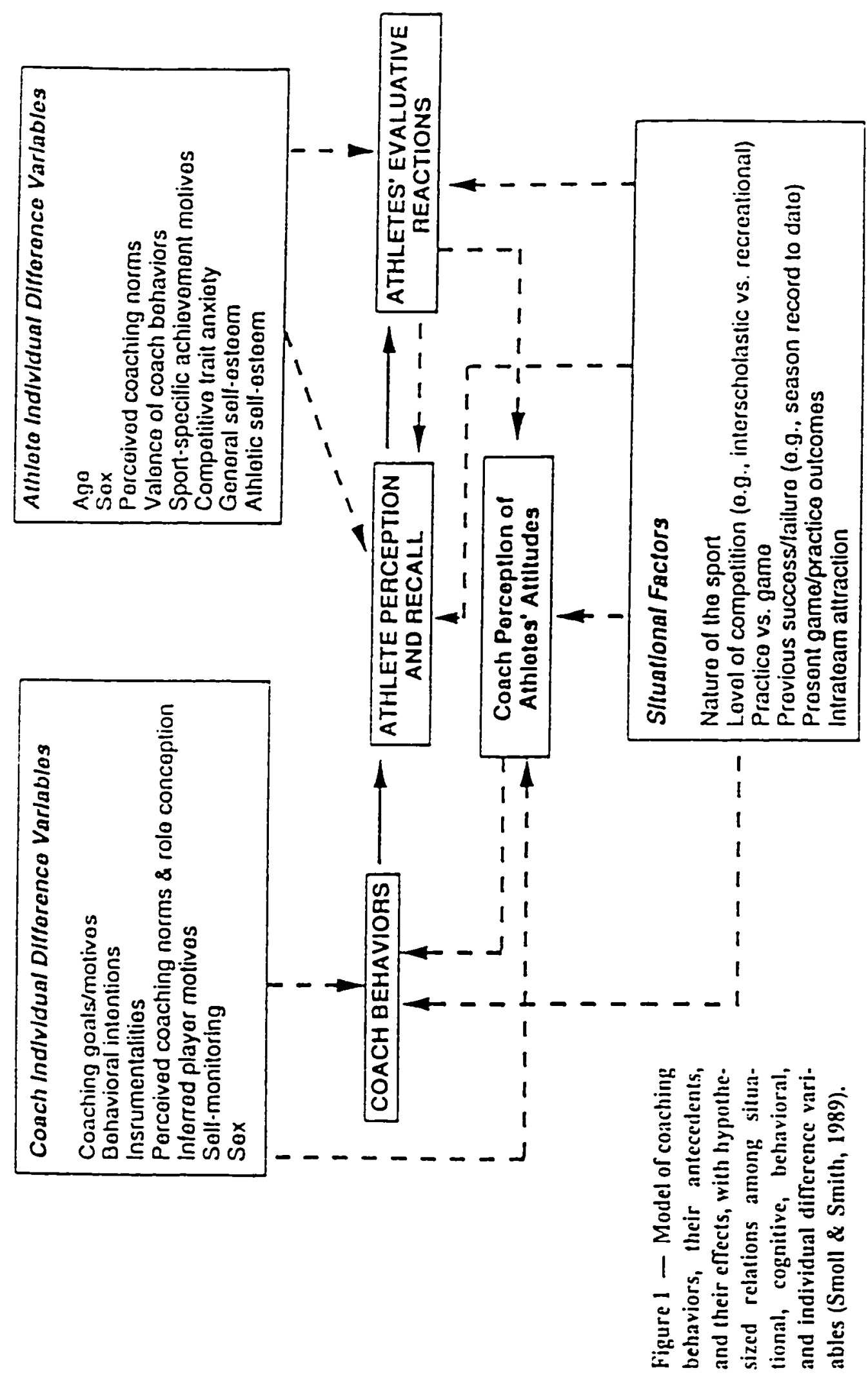


Appendix B

Task and Ego Orientation in Sport Questionnaire (TEOSQ) 


\section{TASK AND EGO ORIENTATION IN SPORT QLESTIONNAIRE \\ (Joan Duda \& John Nicholls)}

Directions: Please read each of the statements listed below and indicate how much you personally agree with each statement by circling the appropriate response.

When do you feel most successful in sport. In other words, when do you feel a sport activity has gone really well for you?

I feel most successful in sport when

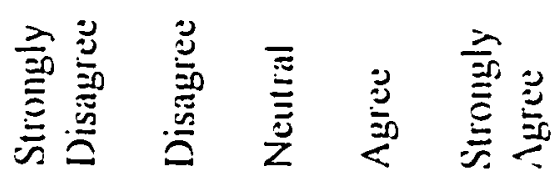

I'm the only one who can do the play or skill. $\quad 1=3+3+5$

I learn a new skill and it makes me want to practice more.

I can do better than my friends

The others can't do as well as me.

I learn something that is fun to do

Others mess up and I don't.

I learn a new skill by trying hard.

I work really hard.

I score the most points/goals/hits, etc

Something I learn makes me want to go and practice more

$\begin{array}{lllll}1 & 2 & 3 & 4 & 5 \\ 1 & 2 & 3 & 4 & 5 \\ 1 & 2 & 3 & 4 & 5 \\ 1 & 2 & 3 & 4 & 5 \\ 1 & 2 & 3 & 4 & 5 \\ 1 & 2 & 3 & 4 & 5 \\ 1 & 2 & 3 & 4 & 5\end{array}$

I do my very best. 
Appendix C

Coaching Behavioral Assessment System (CBAS) 


\section{Class I. Reactive Behaviors}

Response to desirable performance

Reinforcement

Responses to mistakes

Mistake-Contingent Encouragement

Mistake-Contingent Technical Instruction

Punishment

Punitive Technical Instruction

Response to misbehavior

Keeping Control a positive, rewarding reaction (verbal or nonverbal) to a good play or good effort

encouragement given to a player following mistake

instructing or demonstrating to a player how to correct a mistake he/she has made

a negative reaction, verbal or nonverbal, following a mistake

technical instruction following a mistake which is given in a punitive or hostile manner

reactions intended to restore or maintain order among team members

\section{Class II. Spontaneous Behaviors}

Game-related

General Technical Instruction

General Encouragement

Organization

Game-itrelevant

General Communication

spontaneous instruction in the techniques and strategies of the sport (not following a mistake). .

spontaneous encouragement which does not follow a mistake

administrative behavior which sets the stage for play by assigning duties, responsibilities, positions, etc.

interactions with players unrelated to the game 


\section{Appendix D}

Coach's Perception of Own Behavior 


\section{COACHING TECHNIQUES (Smith \& Smoll)}

A number of specific thing that coaches do are described. For each behavior. indicate how often it represents your coaching style during practices.

1. One thing coaches do is Reward or praise their players when they make a good play or try really hard. Circle the number that shows how often you rewarded your players.

$$
\begin{aligned}
& 7 \text { - Almost always } \\
& 6 \text { - Very often } \\
& 5 \text { - Quite often } \\
& \text { 4- Sometimes } \\
& \text { 3- Seldom } \\
& \text { 2- Hardly ever } \\
& 1 \text { - Never }
\end{aligned}
$$

2. Nonreward is when a coach says or does nothing after a player makes a good play or tries hard. Circle how often you did not reward or praise your players for good plays or good effort.

$$
\begin{aligned}
& 7 \text { - Almost always } \\
& 6 \text { - Very often } \\
& 5 \text { - Quite often } \\
& \text { 4- Sometimes } \\
& 3 \text { - Seldom } \\
& \text { 2- Hardly ever } \\
& \text { 1 - Never }
\end{aligned}
$$

3. Sometimes players good and make mistakes. Some coaches give their players support and encouragement after that happens. For example. a coach may say. "That"s OK. don't worry about it. you'll get "em next time." Circle how often you gave your players

\section{Encouragement After Mistakes.}

$$
\begin{aligned}
& 7 \text { - Almost always } \\
& 6 \text { - Very often } \\
& 5 \text { - Quite often } \\
& \text { 4- Sometimes } \\
& \text { 3- Seldom } \\
& \text { 2- Hardly ever } \\
& 1 \text { - Never }
\end{aligned}
$$


4. Another thing a coach might do after a mistake is how or tell the player how to do it right. For example. the coach might tell or show a player the correct way to field a ground ball after he makes an error. This is called Instruction After Mistakes. Circle how often you did this.

$$
\begin{aligned}
& 7 \text { - Almost always } \\
& 6 \text { - Very often } \\
& 5 \text { - Quite often } \\
& \text { 4- Sometimes } \\
& 3 \text { - Seldom } \\
& 2 \text { - Hardly ever } \\
& 1 \text { - Never }
\end{aligned}
$$

5. Punishment includes things like scolding a player who make a mistake. or yelling at him. Circle how often you did this.

$$
\begin{aligned}
& 7 \text { - Almost always } \\
& 6 \text { - Very often } \\
& 5 \text { - Quite often } \\
& \text { 4- Sometimes } \\
& 3 \text { - Seldom } \\
& 2 \text { - Hardly ever } \\
& 1 \text { - Never }
\end{aligned}
$$

6. Sometimes a coach will show a player how to correct a mistake. but in a nasty way. This is the combination of Punishment and Instruction After Mistakes. For example. a coach might angrily say "Catch with two hands. Dummy!" Or. "How often do I have to tell you to watch the ball?" Circle how often you do this.

$$
\begin{aligned}
& 7 \text { - Almost always } \\
& 6 \text { - Very often } \\
& 5 \text { - Quite often } \\
& 4 \text { - Sometimes } \\
& \text { 3- Seldom } \\
& \text { 2- Hardly ever } \\
& 1 \text { - Never }
\end{aligned}
$$


7. Sometimes when a player makes a mistake. coaches say or do nothing. They simply Ignore Mistakes. Circle how often you do this.
7 - Almost always
6 - Very often
5 - Quite often
4 - Sometimes
3 - Seldom
2 - Hardly ever
1 - Never

8. The next thing is called Keeping Control. Coaches do this when their players are misbehaving or not paying attention. For example. if players are fooling around. the coach may say: "Knock it off and pay attention." Circle how often you did this.
7 - Almost always
6 - Very often
5- Quite often
4- Sometimes
3 - Seldom
2 - Hardly ever
I - Never

9. Coaches differ in how much actual teaching or Instructing they do. Circle how often you gave instruction on soccer skills and strategies (not after making mistakes).
7 - Almost always
6 - Very often
5 - Quite often
4 - Sometimes
3 - Seldom
2 - Hardly ever
1 - Never 
10. Some coaches encourage their players a lot. while others do it less often. They may do it at any time. even when things are going well. For example. a coach may clap his hands together and say. "Let's go. you can do it!" Circle how often you gave

Encouragement (not after mistakes).

7 - Almost always

6 - Very often

5 - Quite often

4 - Sometimes

3 - Seldom

2 - Hardly ever

1 - Never

11. The next thing is called Organization. This includes things like reminding players of the starting lineup. making sure the soccer balls are in the right place. and announcing substitutions. Circle how often you kept things organized.

7 - Almost always

6 - Very often

5 - Quite often

4 - Sometimes

3 - Seldom

2 - Hardly ever

1 - Never

12. Some coaches talk or joke with their players a lot. They might talk about uniforms. soccer in general. vacations. or about when they used to play ball. Circle how often you Talked With Players about things in general.

7 - Almost always

6 - Very often

5 - Quite often

4 - Sometimes

3 - Seldom

2 - Hardly ever

1 - Never 
Appendix E

Players' Perception of the Coach's Behavior 


\section{COACHING TECHNIQUES (Smith \& Smoll)}

We want to see how well you remember what kinds of things your head coach did. We also want to know how often your coach did things during practices. In answering the questions, think only about the actions of your head coach.

1. The first thing is called Reward. Coaches reward or praise athletes when they do something well or try really hard. Some coaches give a lot of Reward while others do not. How often did your coach Reward you for good plays or effort? Circle the number that indicates how often your coach Rewarded you.

7 - Almost always

6 - Very often

5 - Quite often

4 - Sometimes

3 - Seldom

2 - Hardly ever

I - Never

2. Nonreward is when a coach does not reward or praise an athlete after he/she makes a good play or tries hard. In other words, the coach ignores it. Circle the number that indicates how often your coach did not reward you when he/she should have.

7 - Almost always

6 - Very often

5 - Quite often

4 - Sometimes

3 - Seldom

2 - Hardly ever

1 - Never

3. Sometimes athletes screw-up and make mistakes. Some coaches give a lot of Encouragement after Mistakes. For example, he/she might say, "That's OK, don't worry about it. "You'll get it next time." Other coaches don't give their athletes much Encouragement after Mistakes.
7 - Almost always
6 - Very often
5 - Quite often
4 - Sometimes
3 - Seldom
2 - Hardly ever
1 - Never 
4. Another thing a coach mich do after a mistake is show or tell the athlete how to do it right. For example, a football coach might tell or show a player the right way to tackle after he misses the ball carrier. This is called Corrective Instruction. Circle how often your coach did this with you.

$$
\begin{aligned}
& 7 \text { - Almost always } \\
& 6 \text { - Very often } \\
& 5 \text { - Quite often } \\
& 4 \text { - Sometimes } \\
& \text { 3- Seldom } \\
& 2 \text { - Hardly ever } \\
& 1 \text { - Never }
\end{aligned}
$$

5. Punishment includes thins like yelling at an athlete who has made a mistake. Punishment is also saying or doing something that hurts an athlete's feelings, or embarrass him/her. Circle how often your coach did this with you.

$$
\begin{aligned}
& 7 \text { - Almost always } \\
& 6 \text { - Very often } \\
& 5 \text { - Quite often } \\
& \text { 4- Sometimes } \\
& 3 \text { - Seldom } \\
& 2 \text { - Hardly ever } \\
& 1 \text { - Never }
\end{aligned}
$$

6. Sometimes a coach will show you how to correct a mistake, but in an unpleasant, punishing way. This is a combination of Corrective Instruction and Punishment. For example, a basketball coach might angrily say, "Pass the ball, don't dribble so much, Dummy!" Circle how often your coach did this with you.
7 - Almost always
6 - Very often
5 - Quite often
4 - Sometimes
3 - Seldom
2 - Hardly ever
1 - Never 
7. Sometimes when you make mistakes is make, coaches say or do nothing. They simple Ignore Mistakes. Circle how often your coach did this with you.

7 - Almost always

6 - Very often

5 - Quite often

4 - Sometimes

3 - Seldom

2 - Hardly ever

1 - Never

8. The next thing is called Keeping Control. Coaches do this when their athletes are misbehaving or not paying attention. For example, if athletes are fooling around, the coach might say, "Knock if off and pay attention." How often did your coach do that?

$$
\begin{aligned}
& 7 \text { - Almost always } \\
& 6 \text { - Very often } \\
& 5 \text { - Quite often } \\
& 4 \text { - Sometimes } \\
& 3 \text { - Seldom } \\
& 2 \text { - Hardly ever } \\
& 1 \text { - Never }
\end{aligned}
$$

9. Some coaches do a lot of teaching. A coach might give Instructions, not because a mistake has been made, but just to show athletes how to do things correctly. How often did your coach give you Instructions?

$$
\begin{aligned}
& 7 \text { - Almost always } \\
& 6 \text { - Very often } \\
& 5 \text { - Quite often } \\
& 4 \text { - Sometimes } \\
& 3 \text { - Seldom } \\
& 2 \text { - Hardly ever } \\
& 1 \text { - Never }
\end{aligned}
$$


10. Coaches don't give Encouragement only after mistakes. They may do it any time, even when things are going well. For example, a coach may clap his/her hands and shout encouragement at any time during practices and games. How often did your coach give you Encouragement?
7 - Almost always
6 - Very often
5 - Quite often
4 - Sometimes
3 - Seldom
2 - Hardly ever
1 - Never

11. The next thing is called Organization. This includes things like keeping practices running smoothly, making sure the equipment is in the right place, announcing substitutions -- in other words, keeping things organized. How often did your coach do things like that?

7 - Almost always

6 - Very often

5 - Quite often

4 - Sometimes

3 - Seldom

2 - Hardly ever

1 - Never

12. Some coaches talk or joke with their athletes a lot. They might talk about school, professional sports, vacations, or about when they used to be an athlete. This is called General Communication. Circle how often your coach did this with you?

7 - Almost always

6 - Very often

5 - Quite often

4 - Sometimes

3 - Seldom

2 - Hardly ever

1 - Never 
Appendix $\mathrm{F}$

Informed Consent 


\section{Statement of Informed Consent}

\section{Invitation to Participate}

You are invited to participate in a study that will investigate coach and athlete interactions. Observations will be conducted of your coach, your teammates. and yourself. The study will be conducted during your practice sessions at Las Positas College during the 1997 soccer season between July 28. 1997 and November 30. 1997. The practices will be videotaped. Also. you and the coach will complete questionnaires before and after the season. All athlete questionnaires will be completed in the absence of the coach. You can be assured that the coach will not receive any information regarding your responses. and that all the information will be analyzed as group data.

\section{Basis for Selection}

You have been selected as a participant because you are a member of the 1997 Las Positas College Men`s Soccer Team at Las Positas College. Livermore, Califomia and are 18 years or older. There will be no anticipated risks as a result from your participation in this study. A meeting will be arranged at the conclusion of the study to share the findings with you and the coach.

Initials 
The athletes and coach may benefit by being told specifically what the researcher was examining and will be given an explanation of the results and significance of the study. The results of this study may be published but no information that could identify an individual participant will be included.

Participation in this study is strictly voluntary. You may refuse to participate in any part of the study. If you decide to participate in the study, you are free to withdraw at any time without prejudice to the soccer team the researcher. San Jose State University or any other participating institution. Each player will receive a signed and dated copy of the consent form.

Any questions concerning the research can be addressed to Jeff Cardinal (408) 24j-6775. or my graduate advisor Susan Wilkinson. Ph.D.. at (408) 924-3034. Complaints about the research may be presented to James Bryant. Ph.D.. Department Chair for the Department of Human Performance. at (408) 924-3010. Questions or complaints about the research. subject's rights. or research-related injury may be presented to Serena Stanford. Ph.D.. Associate Academic Vice President for Graduate Studies and Research. at (408) 924-2+80.

Your signature on this document indicates agreement to participate in this study: The signature of the researcher on this document indicates agreement to include the above named subject in the research and affirmation that the subject has been fully informed of his rights.

Initials 
Subject's Name (Print)

Subject's Signature

Date

Investigator`s Signature

Date 
